\title{
The bli-4 locus of Caenorhabditis elegans encodes structurally distinct kex2/subtilisin-like endoproteases essential for early development and adult morphology
}

\author{
Colin Thacker, Ken Peters, Martin Srayko, and Ann M. Rose \\ Department of Medical Genetics, University of British Columbia, Vancouver, British Columbia, Canada V6T 1Z3
}

\begin{abstract}
Many secreted proteins are excised from inactive proproteins by cleavage at pairs of basic residues. Recent studies have identified several serine endoproteases that catalyze this cleavage in the secretory pathways of yeast and metazoans. These enzymes belong to the kex $2 /$ subtilisin-like family of proprotein convertases. In this paper we describe the molecular characterization of the bli-4 gene from Caenorhabditis elegans, which was shown previously by genetic analysis of lethal mutants to be essential for the normal development of this organism. Sequencing of cDNA and genomic clones has revealed that bli-4 encodes gene products related to the kex2/subtilisin-like family of proprotein convertases. Analysis of bli-4 cDNAs has predicted four protein products, which we have designated blisterases $A, B, C$, and $D$. These protein products share a common amino terminus, but differ at the carboxyl termini, and are most likely produced from alternatively spliced transcripts. We have determined the molecular lesions for three bli-4 alleles $(\mathrm{h199}, \mathrm{h1010}$, and $\mathrm{q508})$ that result in developmental arrest during late embryogenesis. In each case, the molecular lesions are within exons common to all of the BLI-4 isoforms. The original defining allele of bli-4,e937, is completely viable yet exhibits blistering of the adult cuticle. Molecular analysis of this allele revealed a deletion that removes exon 13, which is unique to blisterase A. No RNA transcript corresponding to exon 13 is detectable in the blistered mutants. These findings suggest that blisterase $A$ is required for the normal function of the adult cuticle. The bli-4 gene is a complex locus as evidenced by the characterization of mutant strains and RNA transcripts. Furthermore, our data show that functional redundancy may exist among the various BLI-4 isoforms.
\end{abstract}

[Key Words: Caenorhabditis elegans; KEX2; serine endoproteases; blisters; proprotein processing]

Received November 30, 1994; revised version accepted March 8, 1995.

Many biologically active secreted proteins are synthesized as large inactive precursors. Activation occurs during the secretion process by limited endoproteolytic cleavage, most frequently after pairs of basic amino acids such as Lys-Arg or Arg-Arg (for review, see Docherty and Steiner 1982; Thomas et al. 1988). This cleavage occurs by a general mechanism found in all eukaryotes examined to date, and is catalyzed by a group of serine endoproteases called the kex2/subtilisin-like family of proprotein convertases (for review, see Barr 1991; Seidah and Chrétien 1992). Criteria for assigning enzymes to the family include the ability to process precursor proteins at dibasic sites, and sequence conservation of the protease domain with the bacterial subtilisins and the yeast endoprotease Kex2p. The prototype member of this family of convertases, $\mathrm{Kex} 2 \mathrm{p}$, is a membrane-bound $\mathrm{Ca}^{2+}$. dependent serine endoprotease that cleaves the pro- $\alpha$ mating factor at dibasic sites (Mizuno et al. 1988; Fuller et al. 1989a; for review, see Fuller et al. 1988). Mamma- lian members of the family of convertases include $\mathrm{PCl} /$ PC3 (Seidah et al. 1991; Smeekens et al. 1991), PC2 (Seidah et al. 1990; Smeekens and Steiner, 1990), PC4 (Nakayama et al. 1992; Seidah et al. 1992), PC5/PC6 (Lusson et al. 1993; Nakagawa et al. 1993), PACE4 (Keifer et al. 1991), and human furin (hFURIN; Roebroek et al. 1986; Fuller et al. 1989b; van den Ouweland et al. 1990; Wise et al. 1990). Defining the biological significance of individual convertases has been stymied by the lack of evidence demonstrating substrate specificity. For example, when removed from their biological context, many of the endoproteases are able to process the same substrates, raising the question whether such a functional redundancy exists among the family members in vivo. Some insight into defining functionality has been provided by examining the expression patterns and localization of the individual convertases. From such analyses it has been shown that substrate specificity can be influenced by both restricting expression to particular tissues 
and compartmentalization of the individual enzymes to specific intracellular locations (Seidah and Chrétien 1992).

Restricted expression is exhibited by $\mathrm{PC} 1 / \mathrm{PC} 3$ and PC2 to endocrine and neuroendocrine tissues (Seidah et al. 1990, 1991; Smeekens and Steiner 1990; Smeekens et al. 1991), whereas PC4 is restricted to the testis (Nakayama et al. 1992; Seidah et al. 1992). These observations imply a distinct functionality for the three convertases within the regulated secretory pathway. In contrast, both hFURIN and PACE4 are expressed in a broad range of tissues suggesting that these convertases are required for processing activity within the constitutive secretory pathway (Roebroek et al. 1986; Bresnahan et al. 1990; van den Ouweland et al. 1990; Van de Ven et al. 1990; Kiefer et al. 1991). PC5/PC6, like hFURIN and PACE4, exhibits a widespread tissue distribution. However, levels of expression are predominant in intestinal tissue (Lusson et al. 1993; Nakagawa et al. 1993). This may suggest that PC5/PC6 is active in both the constitutive and regulated secretory pathways. Clearly, an added complication in defining substrate specificity arises within cells in which regulated and constitutive pathways are active, as both types of convertase will be produced.

Compartmentalization may also influence the control of proprotein convertase substrate specificity and activity. Individual enzymes are sequestered in separate intracellular compartments. Localization of the individual processing enzymes appears to be a function of the structural differences between each family member. This has been demonstrated clearly for hFURIN, which is concentrated in the trans-Golgi network (TGN) (Molloy et al. 1994). hFURIN, like all members of the kex2/subtilisinlike family, is synthesized as an inactive zymogen (Leduc et al. 1992; for review, see Seidah and Chrétien 1992). Exit from the endoplasmic reticulum and transport to the TGN appears to coincide with activation of the catalytic function of the enzyme. Furthermore, the intracellular distribution of hFURIN is dynamic. The enzyme is cycled to and from the TGN by the cell surface within coated vesicles. At least in part, the trafficking signals required for cycling are encoded within the cytoplasmic tail of hFURIN (Molloy et al. 1994).

The identification of kex $2 /$ subtilisin-like proprotein convertases in simple animal systems that are amenable to classical and molecular genetic manipulation provides an alternate approach to examine the role of these important enzymes. Recently, genes that encode kex 2 /subtilisin-like endoproteases have been isolated from Drosophila melanogaster and the nematode Caenorhabditis elegans. Two genes isolated from Drosophila, called Dfur-1 (Roebroek et al. 1992, 1994; also called dKLIP-1; Hayflick et al. 1992), and Dfur-2 (Roebroek et al. 1992), encode convertases with sequence similarity to hFURIN. Genes isolated from $C$. elegans include CELPC2, which shows sequence similarity to PC2 (Gómez-Saladín et al. 1994), and an additional gene identified by the genome sequencing group that most closely resembles hFURIN (Waterston et al. 1992; C. Thacker and A.M. Rose, unpubl.). At present, no known mutations within these genes have been reported.

Previously, this laboratory described the genetic analysis of mutants within the bli-4 gene of C. elegans. In this report we present the characterization of the bli-4 gene and show that it encodes serine endoproteases that belong to the $\mathrm{kex} 2 /$ subtilisin-like proprotein convertase family. bli-4 was first identified by a recessive mutant that results in the formation of fluid-filled separations, or blisters, of the adult cuticle layers (Brenner 1974). Characterization of the $e 937$ mutation revealed it to be incompletely penetrant; $85 \%-90 \%$ of $e 937$ homozygotes exhibit the blistered phenotype (Brenner 1974; Peters et al. 1991). Subsequently, 13 additional recessive mutants were isolated, all of which are lethal, arresting development in late embryogenesis (Rose and Baillie 1980; Howell et al. 1987; Peters et al. 1991; C. Thacker, M. Srayko, and A.M. Rose, unpubl.). The associated lethality indicates an essential role for bli-4 in embryogenesis in addition to its role in the production or maintenance of the adult cuticle. Here we show that the bli-4 gene encodes at least four proprotein convertases that arise by alternative splicing at the 3 ' end, generating enzymes with different structural properties. The four gene products share the protease domain yet differ at the carboxyl termini. Alternative splicing generates isoforms with structural similarities to each of the mammalian proprotein convertases that participate in both the regulated and constitutive secretory pathways. Molecular lesions responsible for three lethal mutants were identified within coding sequences common to all of the BLI-4 isoforms. Removal of the unique 3' exon of one isoform results in the blistered phenotype. Our results also suggest that incomplete penetrance of blistering exhibited by the $e 937$ mutation may result from functional redundancy among the various bli-4 gene products. This is the first identification of mutants in a kex2/subtilisin-like gene in a multicellular organism, and the first direct evidence that a member of this gene family is essential for development.

\section{Results \\ Mutants display both a viable cuticular defect and lethality}

Previous genetic analysis in our laboratory has demonstrated that bli-4 is a complex locus (Peters et al. 1991). Mutations within the gene have been categorized into three classes depending on mutant phenotype and intracomplementation analysis (Table 1). The first mutant class is represented by the recessive allele $e 937$, which originally defined the locus (Brenner 1974), and exhibits blistering of the adult cuticle but is otherwise completely viable (Fig. 1B). The $e 937$ mutation shows incomplete penetrance such that $\sim 90 \%$ of homozygous animals display the blistered phenotype. Currently, there are 13 known recessive alleles of bli-4 that result in lethality. These alleles exhibit a complex pattern of intragenic complementation and have been grouped into two 
Table 1. Intracomplementation between bli-4 alleles

\begin{tabular}{llcc}
\hline $\mathrm{a} / \mathrm{b}^{\mathrm{a}}$ & Class I $^{\mathrm{a}, \mathrm{b}}$ & Class II $^{\mathrm{a}}$ & Class III $^{\mathrm{a}}$ \\
\hline Class I & Bli $(90 \%)$ & - & - \\
Class II & Bli $(100 \%)$ & arrest threefold & - \\
Class III & wild type & arrest threefold & $\begin{array}{c}\text { arrest threefold/ } \\
\text { Ll larvae }\end{array}$ \\
\hline
\end{tabular}

${ }^{a}$ Class I mutant is represented by $e 937$. Class II mutants are represented by h1010 and $q 508$. The class III mutant is represented by the single allele $s 90$.

bercentage of blistered animals. Approximately $90 \%$ of e937 homozygotes exhibit the blistered phenotype. The blistered cuticle phenotype is fully penetrant in the $e 937 /$ class II lethal mutant heteroallelic combination.

separate classes based on their complementation with each other and with $e 937$ (Table 1). Twelve lethal alleles that do not complement $e 937$ represent class II mutants and arrest development in late embryogenesis during elongation of the embryo. An example of the terminal phenotype of a class II mutant is shown in Figure 1D. Arrested animals appear fully differentiated yet are unable to complete elongation (Fig. 1, cf. C and D). All class II mutants examined become vacuolated, particularly in the head region (Fig. ID). A single recessive lethal allele, $s 90$, complements $e 937$ and represents a third bli-4 mutant class (class III). Normally, one would interpret the complementation of $e 937$ by the class III allele to mean that these mutations are in two separate genes. However, $s 90$ fails to complement any of the class II lethal alleles, suggesting that the mutation does reside in the same gene. Most animals homozygous for the $s 90$ mutation arrest at the same stage of development and are indistinguishable in phenotype from the class II lethal mutants. However, $\sim 30 \%$ of the animals hatch and later arrest as early L1 larvae with a distinctive "dumpy" appearance (Fig. 1F). Apart from the obvious morphological defect, the larvae respond to touch and pharyngeal pumping is observed, albeit at a very reduced rate. These dumpy animals persist for several days before dissolution. The mutant phenotypes observed for both the class II and III lethal alleles are similar to those seen for cuticle-defective mutants that elongate normally, but subsequently retract in length (Priess and Hirsh 1986). Isolation of lethal mutants in bli-4 implies an essential function for the gene, in contrast to the cuticle defect associated with the original $e 937$ mutation. The interesting genetics associated with the various mutants and the intriguing incomplete penetrance of the blistered mutant prompted us to characterize the gene further.

\section{The bli-4 locus is situated in cosmid K04F10}

To clone the bli-4 gene, we aligned the genetic map position with the physical map as described in Materials and methods (Fig. 2). Using the cosmid K04F10, we were able to identify DNA rearrangements associated with two bli-4 mutants, h1010 and $e 937 . h 1010$ was isolated in a precomplementation screen for bli-4 mutations in a mut- 6 background (Peters et al. 1991). mut-6 mobilizes the transposable element Tc1 (Mori et al. 1988); therefore, h1010 was presumed to contain a transposon insertion in bli-4. We identified the Tc1 insertion site in a 1.3-kb EcoRI fragment (Fig. 3A; see below). Analysis of genomic DNA isolated from $e 937$ homozygotes using $\mathrm{K} 04 \mathrm{~F} 10$ as probe revealed a deletion of $3.5 \mathrm{~kb}$ (Fig. 3A). Thus, two DNA rearrangements associated with two independent bli-4 mutations were detected by the cosmid K04F10.

\section{All mutant classes of bli-4 are rescued by K04F10}

To confirm that K04F10 contained all the information required for bli-4 expression, we used a transgenic nematode strain that carries this cosmid to test for rescue of the various mutant phenotypes. The transgenic strain (kindly provided by J. McDowall, University of British Columbia, Vancouver) carries K04F10 as an extrachromosomal array along with the dominant selectable marker rol-6 that causes worms to roll along their longitudinal axis (Mello et al. 1991). The K04F10-containing array ( $h E x 4)$ was essentially used as a free duplication to provide wild-type function in a mutant background. Specifically, $h E x 4$ was transferred by genetic crosses to lethal strains carrying a bli-4 mutation and flanking markers. Successful rescue of the lethal phenotype was indicated by the appearance of viable morphological mutants in the resulting outcrossed progeny. Normally the flanking markers would be masked by the lethal phenotype. Using this approach, transfer of the extrachromosomal array to the noncomplementing class II lethal mutant h1010 [genotype unc-63 bli-4(h1010) unc-13; szTI] resulted in the generation of Unc-63 Unc-13 Rol-6 progeny. In addition, transfer of $h E x 4$ to the complementing class III lethal $s 90$ [genotype bli-4(s90) unc-13; sDp2], gave rise to Unc-13 Rol-6 progeny. These results showed that the cosmid is able to rescue the lethal phenotype of both classes of bli-4 mutation.

Transfer of $h E_{X} 4$ to blistered $e 937$ animals resulted in the establishment of several roller lines. The progeny from each of these lines consisted of blistered non-Rol- 6 and nonblistered Rol- 6 animals. Because extrachromosomal arrays segregate in a non-Mendelian fashion (Mello et al. 1991), we would expect to see blistered nonRol-6 progeny in the roller lines because they are homozygous for the bli-4(e937) mutation. We have maintained these strains for many generations and have never observed blistering of the Rol-6 animals, indicating that the cosmid array also rescued the blistered phenotype of e937. Transfer of an extrachromosomal array containing only the rol-6 plasmid to $e 937$ animals failed to rescue the blistered phenotype. These experiments showed that K04F10 can rescue the mutant phenotype for all classes of bli-4 mutation. Therefore, we concluded that the cosmid contains the bli-4 gene.

\section{Isolation and characterization of bli-4 cDNAs}

The 1.3-kb EcoRI genomic DNA fragment from K04F10 that identified the DNA rearrangement in h1010 was 


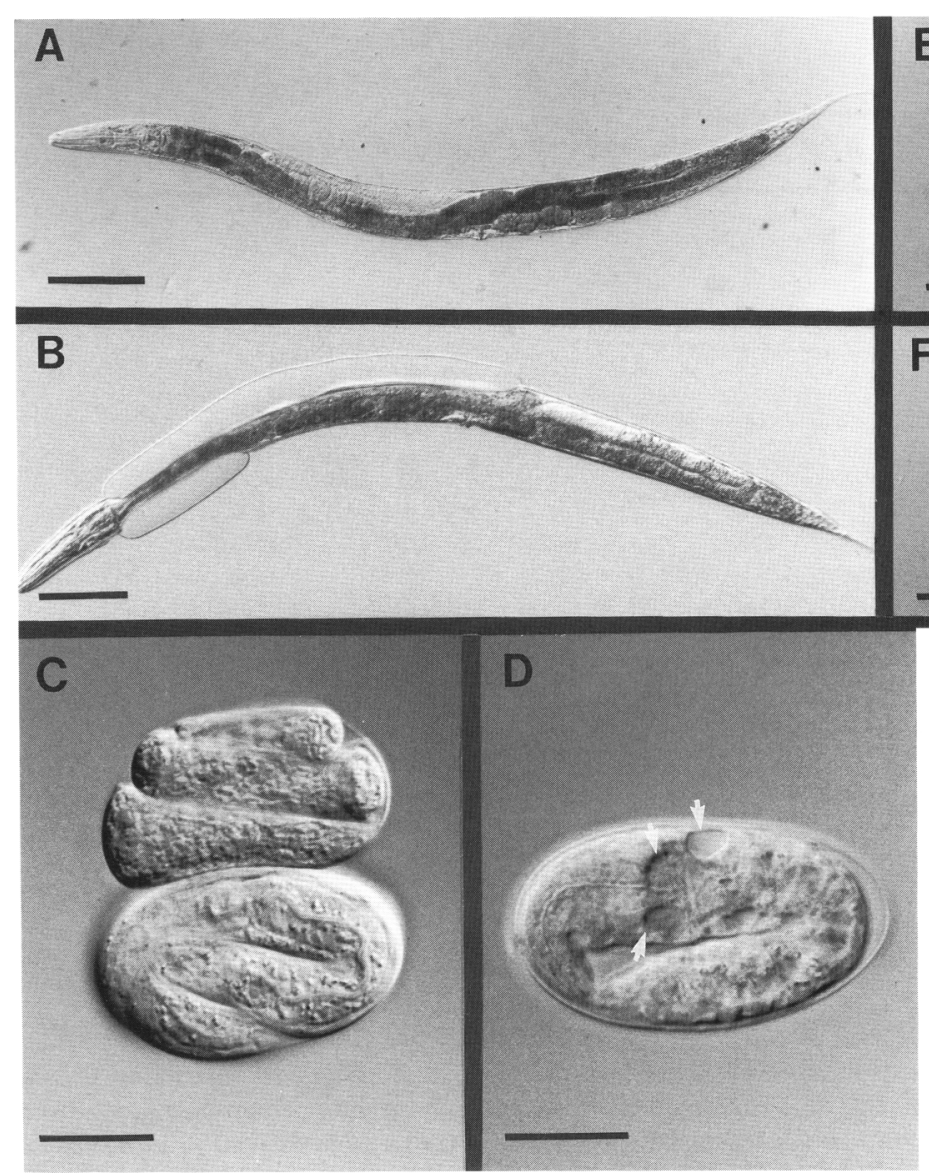

used as a probe to screen the cDNA library of Barstead and Waterston (1989) identifying six cDNA clones. Additional cDNAs were identified as part of the ongoing genome sequencing project (Waterston et al. 1992; Y. Kohara, pers. comm.). The clones were placed into four groups according to their structural similarities and have been designated blisterase A, blisterase B, blisterase C, and blisterase D (Figs. 3 and 4). Blisterase A cDNAs (six clones) encode a putative protein of 670 amino acids. A single blisterase B cDNA contains a 2419-bp insert, including a large open reading frame, which begins with the same potential ATG start codon as blisterase A, that

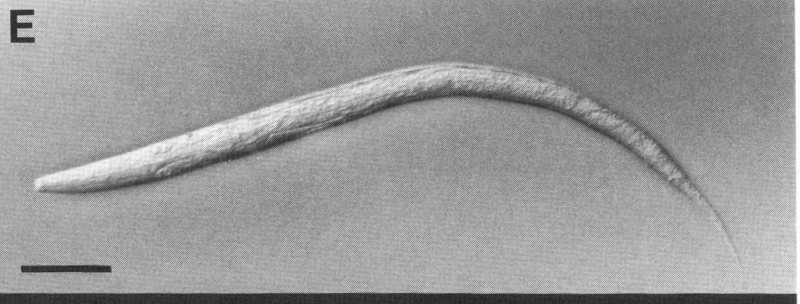

$\mathbf{F}$

Figure 1. Characteristic phenotypes of the three bli-4 mutant classes using Nomarski photomicrographs. (A) Wild-type adult. $(B)$ e937 homozygous (class I) adult hermaphrodite showing the blistered cuticle. (C) Wild-type threefold embryos showing the typical elongated morphology. (D) An arrested bli-4(q508) embryo representative of the terminal phenotype associated with the class II lethal mutants. Note the vacuolated cells within the head region (arrows). (E) An unc13(e51) L1 larva. $(F)$ The single class III allele $s 90$ [genotype bli-4 (s90) unc-13 (e51)] showing the arrested "dumpy" phenotype depicted by $\sim 30 \%$ of animals homozygous for the mutation. $(A, B)$ Bar, $100 \mu \mathrm{m}$; $(C-F)$ bar, $10 \mu \mathrm{m}$.

can encode a protein of 730 amino acids. A single blisterase C cDNA contains a 2659-bp insert, which contains an open reading frame of 2481 bp that begins with the same initiator methionine as blisterases A and B, predicting a protein of 827 amino acids. Three blisterase $\mathrm{D}$ clones were identified, although all represent partial cDNAs that are missing sequences at the $5^{\prime}$ end. The longest clone begins at nucleotide 741 of blisterase $B$ (Fig. 4A). The reverse transcriptase-polymerase chain reaction (RT-PCR) analysis indicated that the bli-4 transcripts are trans-spliced to the SLl splice leader (Krause and Hirsh 1987/. The RT-PCR results, together with

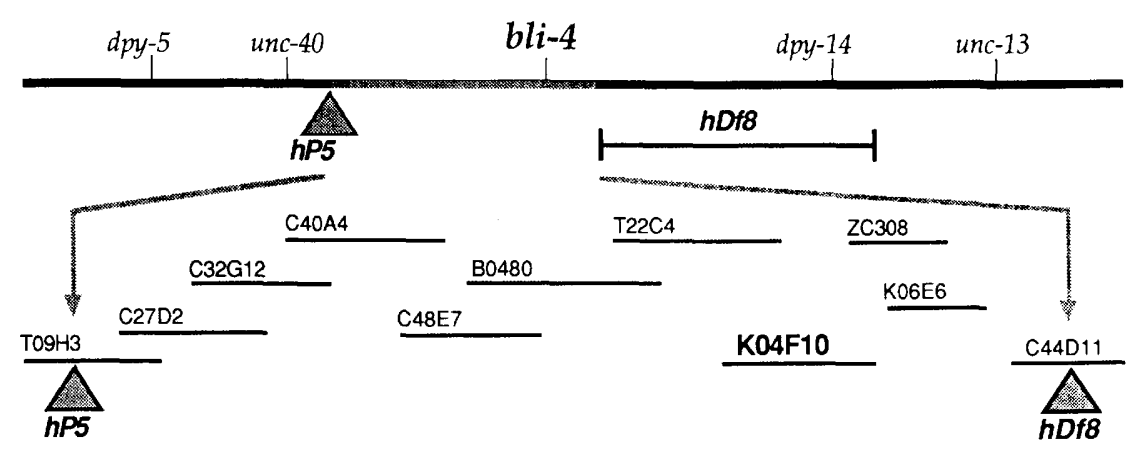

Figure 2. Genetic and physical maps of the bli-4 region. bli-4 was mapped genetically between the N2/BO strain RFLP hP5 and the left breakpoint of the deletion $h D f 8$ (see Materials and methods). This interval is spanned by $200 \mathrm{~kb}$ of contiguous cosmid clones, except for a small gap between K06E6 and C44D11, which is spanned by yeast artifical chromosome (YAC) clones (Coulson et al. 1986, 1988). The positions of $h P 5$ and the left breakpoint of $h D f 8$ in the physical map are indicated by shaded arrowheads. All of the cosmids shown were used to probe genomic DNA isolated from several mutants. 


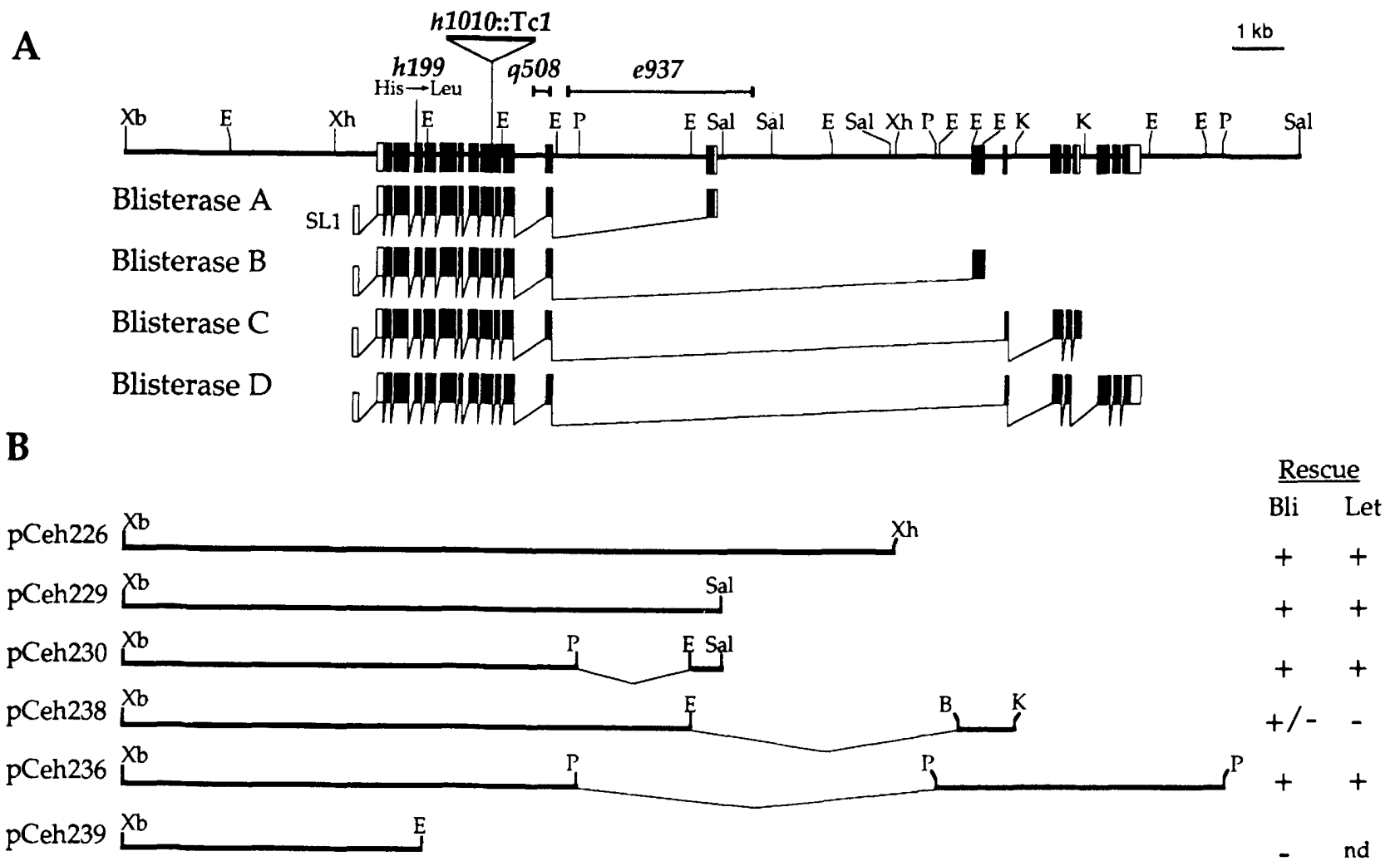

Figure 3. Genomic organization of the bli-4 gene and the results of phenotypic rescue experiments. $|A|$ A partial restriction map of $\sim 15 \mathrm{~kb}$ of genomic DNA containing the bli-4 gene is shown at the top. The structure is based on complete genomic sequencing of exons 1-12, $2 \mathrm{~kb}$ of genomic sequence around exon 13, and $4.2 \mathrm{~kb}$ including exons 14-21. The amino acid substitution in $h 199$, the site of the Tc1 insertion in h1010, the 366-bp deletion in $q 508$, and the $3.5-\mathrm{kb}$ deletion of $e 937$ are indicated. (Bottom) The four groups of cDNA clones. Solid boxes indicate exons; open boxes represent untranslated sequences, including the SLl trans-splice leader sequence (Krause and Hirsh 1987). (B) Representation of plasmid constructs used for rescue of the blistered and lethal (both class II and class III alleles) mutant phenotypes by germ-line transformation. $(+\mid$ Complete rescue $; 1+1-\mid$ incomplete rescue; $(-)$ no rescue; (nd) not done. Restriction enzymes: (Xb) XbaI; (Xh) XhoI; (P) PstI; (Sal) SalI; (E) EcoRI; (K) KpnI; (B) BamHI. Some restrictions sites used for cloning have been omitted for clarity.

data obtained by Northern blot analysis (see below), suggest that all blisterases share the same $5^{\prime}$ sequences.

All cDNA clones are complete at their $3^{\prime}$ ends, terminating with a poly(A) tract. However, all four groups have different $3^{\prime}$ ends. The point of divergence is after nucleotide 2151 of the blisterase B cDNA sequence as shown in Figure 4. We determined the genomic intron/ exon organization of the bli-4 gene by partial restriction mapping and sequence analysis and found that the four cDNA groups diverge from each other at an intron/exon boundary (see Fig. 3A). This implies that the different predicted isoforms are produced by alternative splicing. An interesting characteristic common to both the blisterase $B$ unique $3^{\prime}$ exon and exon 18 , which is specific to blisterase $\mathrm{C}$, is the extremely short $3^{\prime}$-untranslated region (3' UTR). The 3' UTRs for these cDNAs are only 23 and 31 nucleotides long, respectively (Fig. 4), which is unusual, at least when compared with other $C$. elegans genes.

Rescue of bli-4 mutant phenotypes by a subset of gene products

The functional activity of each BLI-4 isoform was exam- ined by using transgenics carrying various subclones of K04F10. A number of constructs were generated that contain genomic sequences encoding one or more of the bli-4 gene products (see Fig. 3B). Complete rescue of the class II $(h 199, q 508)$ and class III $(s 90)$ lethal phenotypes and the blistered phenotype was obtained using the constructs that contain sequences encoding only the blisterase A isoform (pCeh226, pCeh229, and pCeh230). Complete rescue was also obtained by plasmid pCeh236, which encodes isoforms $\mathrm{B}, \mathrm{C}$, and D. In contrast, expression of blisterase $B$ alone ( $\mathrm{pCeh} 238$ ) was unable to rescue the lethal phenotypes of both class II and III mutants. However, the same plasmid rescued partially the blistered phenotype suggesting functional redundancy between isoforms $\mathrm{A}$ and $\mathrm{B}$ in adult nematodes.

\section{bli-4 encodes kex2/subtilisin-like serine endoproteases}

A search of the GenBank, PIR, and SWISS-PROT data bases revealed significant amino acid sequence similarity between the predicted BLI- 4 sequence and members of the kex2/subtilisin-like family of proprotein-converting enzymes. The sequence similarity is most striking 
$\mathbf{A}$

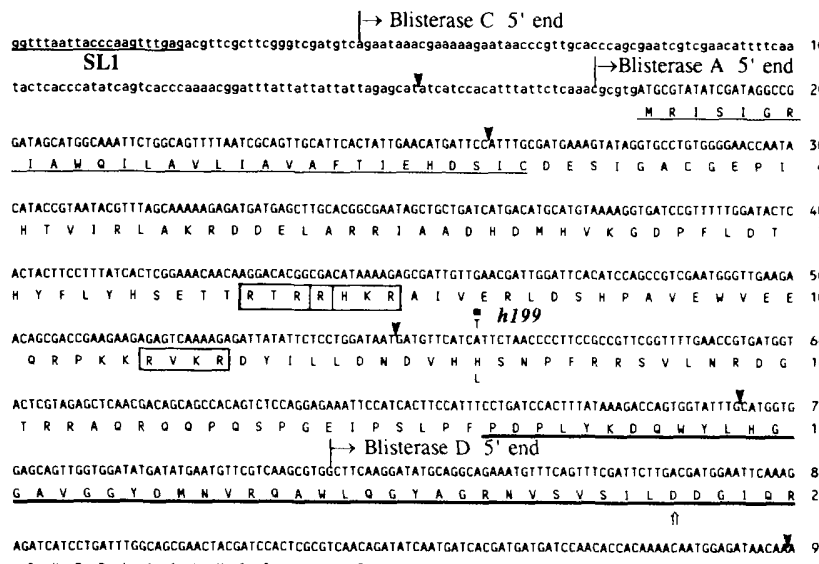

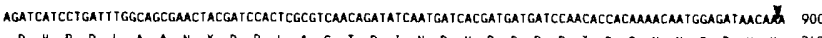

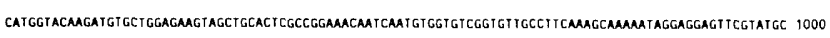

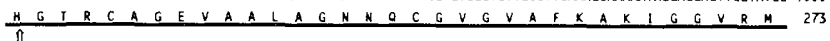

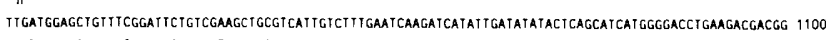

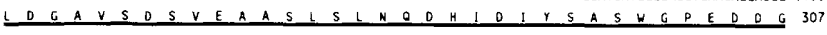

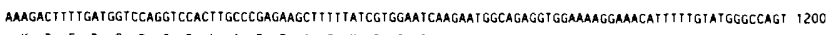
$K$ I F D G P G P LAREA F Y R G

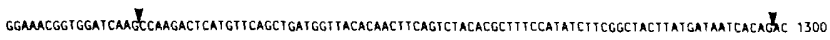

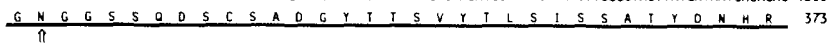

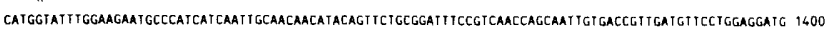

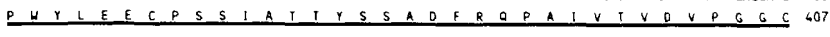

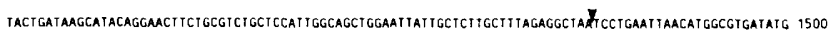
$I$ D K H T G I S A S A P L A A G I I A L A L E A H P E L I H R D F
$\pi$

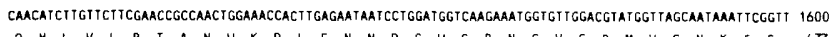
足 L L L R T A H W K P L E N N P G W S R N G V G R M V S N K F G 473

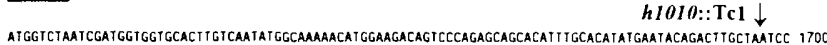
Y G L I D G G A L V N M A K T VK T V P E O H I C T Y E Y L A P 507

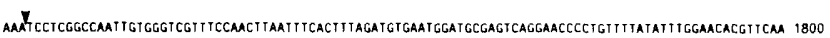
N P R P I V G R F O L N F T L D V NG C E S G F P V L Y L E H V O 540

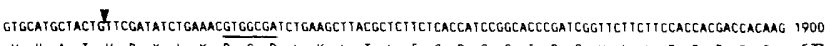

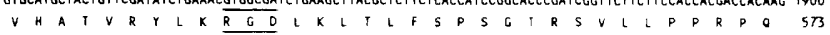

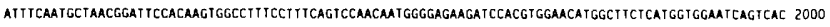

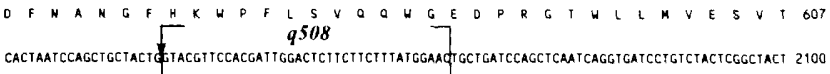
T N PA A T E E F H D W T L L L Y G J A D PAA O S G D P V Y S A T 040

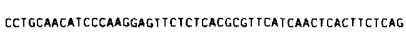

P A I S O G V L S R VHOL TSO

Blisterase $\mathrm{A}$ unique $3^{\circ}$ end

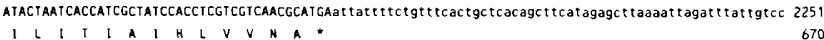

cttratcct ggttacgat gtgttctgaaact tgictccccattetctgtgtcattttccett tgacctcactatgatgaatactetttacgagaaaa 2351 зааааааааaаaаa

Blisterase $B$ unique $3^{\prime}$ end

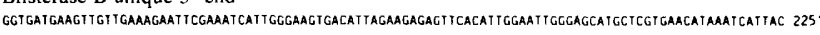

G DEV VERI R M HEVTLEESS H WE HAREMKSL 690

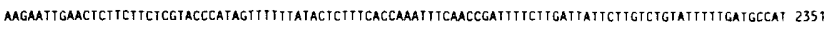
- E L N S S S R T H S F L Y S F T K F O P I F L I I L V E I F D A 1726

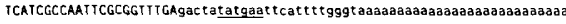

H R Q F A V

Blisterase $C$ unique $3^{\prime}$ end

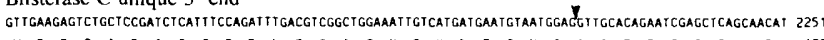
VEE S A P I S F P D L T S A G N C H D E C N G G C TESSSSA I 690

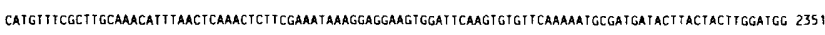
S C F A C K H L T O TL R N K G G S G F K C V O K C O D T Y Y Y L D G 724

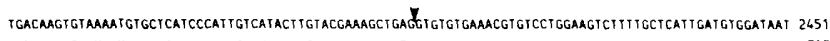
D K C K H C S S A C H T C T K A E V C E T C P G S L L L I D V O M 757

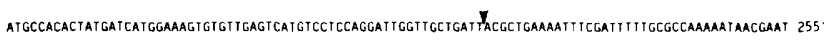
A P H Y D H G K C VES C P P G L VA D Y A E NF D F C A K N NE 790

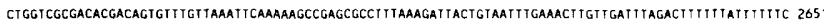
$S$ G R D I I T V F V K F K K $P$ S S A F K

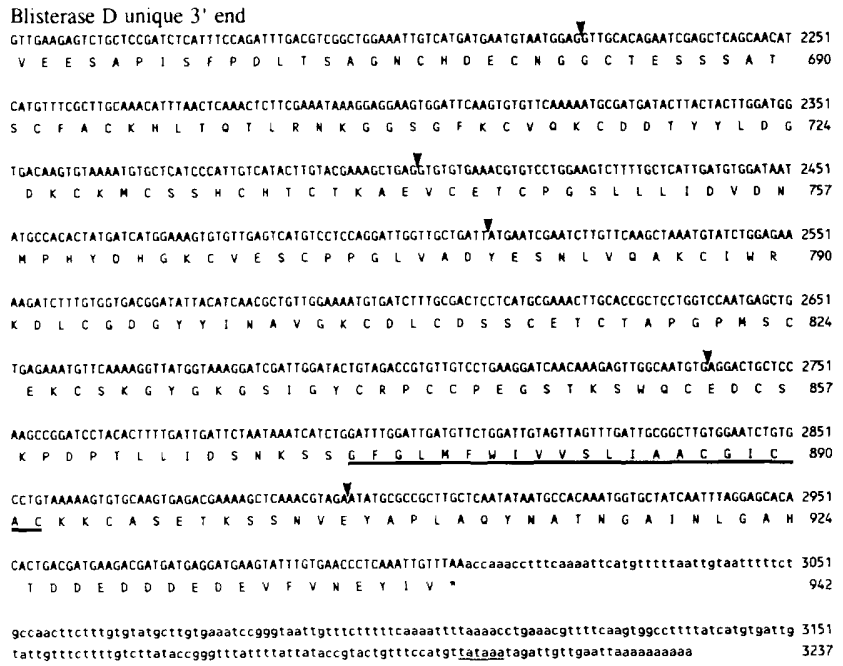

3237

\section{B}

Blisterase $C$ variant coding sequence

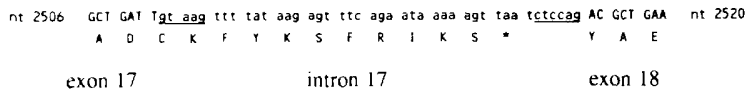

Figure 4. Nucleotide and predicted amino acid sequence of the bli-4 cDNAs. $(A)$. The common and unique 3 ' sequences of each bli- 4 gene product is presented. The $5^{\prime}$ ends of representative blisterase A, C, and D cDNAs are indicated by right-angled arrows SLl is the splice-leader sequence (Krause and Hirsh 1987). Results obtained using Northern blot analysis suggest that blisterase D has the same $5^{\prime}$ end as blisterase B. The putative amino-terminal signal sequence is underlined. The kex2/subtilisin-like protease domain is double underlined, as is the hydrophobic amino acid sequence in the blisterase D specific $3^{\prime}$ end. The potential cell attachment site Arg-Gly-Asp (RGD) is overlined and underlined. The potential autocatalytic cleavage sites (Arg-X-Lys/Arg-Arg) have been boxed. Upward open arrows denote catalytically important amino acid residues Asp, His, Asn, and Ser. Solid downward arrowheads denote the position of intron/exon boundaries. Polyadenylation sites are underlined. The $\mathrm{A} \rightarrow \mathrm{T}$ transversion identified as the lesion in $h 199$ causing the His-127 $\rightarrow$ Leu substitution is indicated. The site of the Tc1 insertion identified associated with the h1010 mutation is labeled by a downward arrow (between nucleotides 1696 and 1697). Thirty-seven coding nucleotides that are deleted in the class II mutant $q 508$ are indicated within the square brackets. $(B)$ The putative carboxyl terminus of the variant blisterase $C$ transcript. Amino acids potentially encoded within intron 17 are shown. The splice donor and acceptor are underlined. 
within the kex2/subtilisin-like protease domain (Figs. 5 and 6). hFURIN shows the most extensive conservation with the blisterases in this region, exhibiting $72 \%$ sequence identity (Figs. 5 and 6). The blisterase protease domain includes catalytically important amino acids Asp-202, His-241, Asn-342, and Ser-415, which are present in all members of the kex2/subtilisin-like endoprotease gene family (with the exception of PC2).

Although the sequence similarity is restricted primarily to the protease domain, the blisterase proteins share structural features outside this region with the other kex2/subtilisin-like endoproteases (Fig. 6). These conserved structural similarities include pairs of basic residues on the amino side of the protease domain that are potential sites of activation by autoproteolytic cleavage. This has been demonstrated in the bacterial subtilisins
(Power et al. 1986; Ikemura and Inouye 1988) and, recently, for hFURIN (Hosaka et al. 1991; Molloy et al. 1992, 1994). The conservation of a tripeptide Arg-GlyAsp (RGD) motif representing the minimal recognition sequence required for cell attachment located in a similar position relative to the active site [with the exception of Kex2p, which has the sequence Arg-Gly-Thr at this position (Fuller et al. 1988)] is also conserved. Furthermore, certain members of the kex 2 /subtilisin-like family, including hFURIN (Roebroek et al. 1986), PACE4 (Kiefer et al. 1991), PC5/PC6 (Lusson et al. 1993; Nakagawa et al. 1993), Dfurin-1CRR (Roebroek et al. 1994), and Dfurin-2 (Roebroek et al. 1992), have a Cys-rich region toward the carboxyl terminus [Kex $2 \mathrm{p}$ is Ser-Thr rich in this region (Fuller et al. 1988)]. Blisterases C and D both encode a Cys-rich region. Blisterase $C$ contains a
Figure 5. Alignment of the protease domain of BLI-4 (residues 162-443), with PACE4 (residues 161-448; Keifer et al. 1991), hFURIN (human furin; residues 114-396; Wise et al. 1990), hPC2 (human PC2; residues 122-412; Seidah et al. 1990), mPC3 (mouse PC3; residues 122-410; Seidah et al. 1991), Dfurinl (Drosophila furin; residues 333-615; Roebroek et al. 1994), and Kex2p (yeast; residues 134-411; Mizuno et al. 1988). Residues that are identical to the BLI-4 sequence have been boxed and gaps introduced to give maximum sequence alignment. Shaded residues indicate the catalytically important amino acids Asp, His, Asn, and Ser.

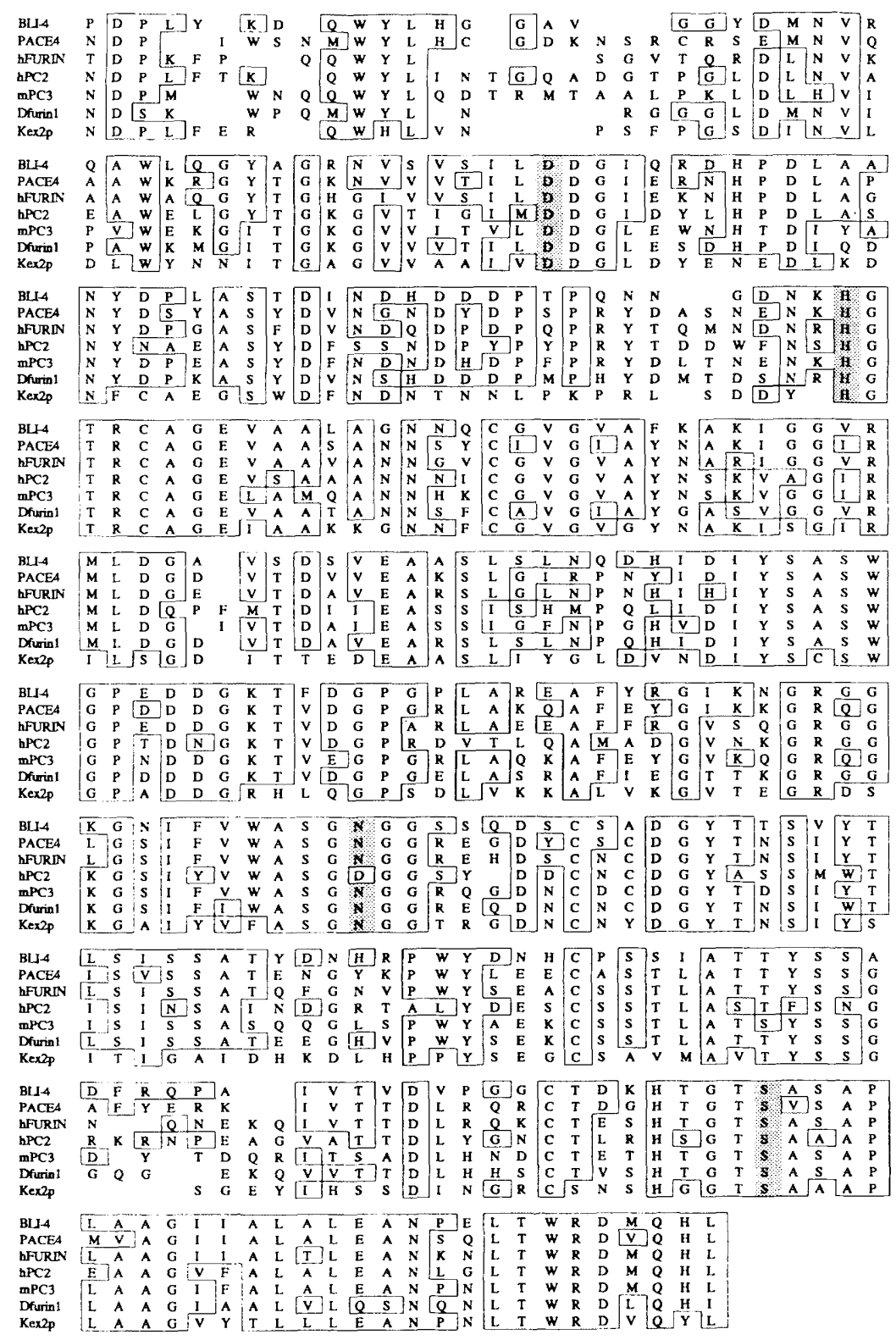




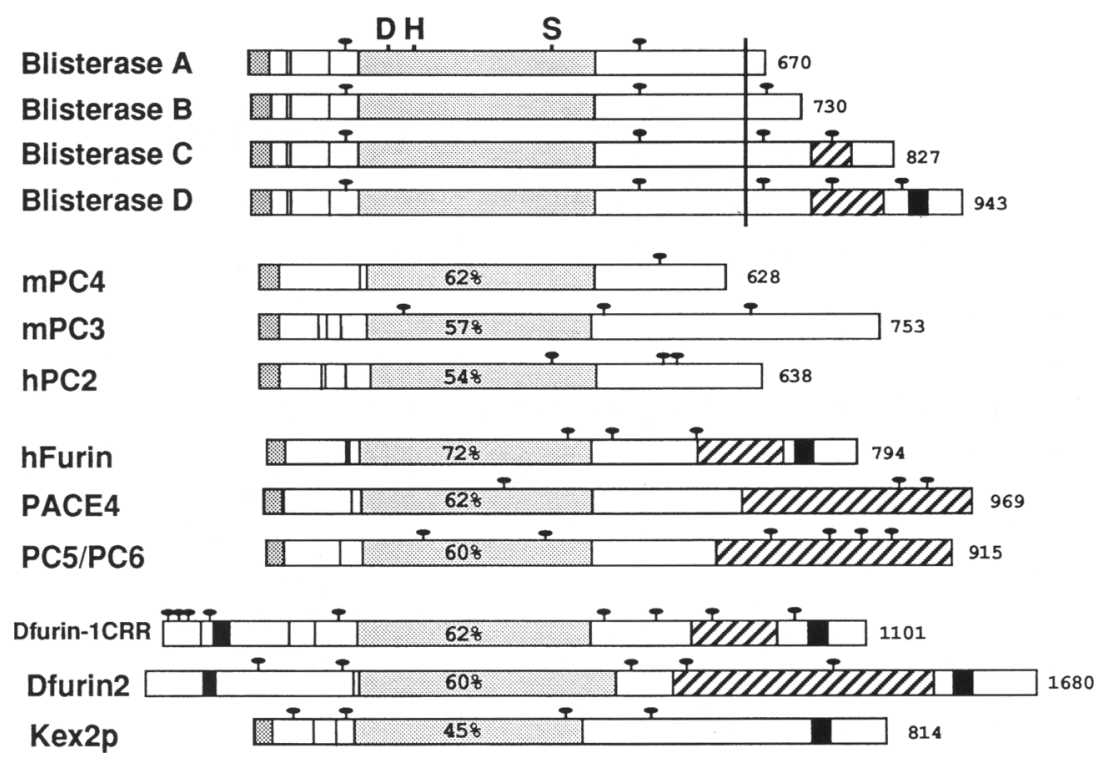

Figure 6. Schematic structural comparison between the BLI-4 products and other members of the kex2/subtilisin-like family of endoproteases. Structural features and relative lengths of the predicted BLI-4 isoforms, mPC4, mPC3, hPC2, hFURIN, PACE4, hPC5/hPC6, Dfurin-1CRR, Dfurin-2, and Kex2p polypeptides are shown. Secretion signal peptides are shown as shaded; protease domains are shown stippled with the positions of the catalytically important amino acids Asp, His, and Ser indicated by D, H, and S; the Cys-rich regions are depicted as hatched boxes; transmembrane domains are shown as solid boxes. Ovals indicate potential $\mathrm{N}$-linked glycosylation sites. The potential autocatalytic cleavage sites are shown as vertical bars on the amino side of the protease domain. The numbers within the protease domains represent the percentage of identical residues when compared with the BLI-4 isoforms. single Cys-rich region (encoded by exon 17), whereas blisterase $\mathrm{D}$ has two Cys-rich domains encoded by exons 17 and 19.

Hydrophobicity analysis (Kyte and Doolittle 1982) of the blisterases revealed two major hydrophobic domains. The first is a short hydrophobic domain at the amino terminus with features typical of a signal sequence. A second hydrophobic sequence is located near the carboxyl terminus of blisterase $\mathrm{D}$ and is followed by a highly acidic 48 -amino-acid domain (Figs. 4 and 6). Similar hydrophobic domains followed by acidic residues are found in Kex2p, hFURIN, Dfurin-1-CRR, and Dfurin-2. Taken together, this information suggests that the hydrophobic domain of blisterase $\mathrm{D}$ is likely to be a transmembrane domain. The remaining BLI-4 isoforms all contain several hydrophobic residues located toward the carboxyl termini, although the hallmarks typical of a transmembrane domain are not apparent.

The overall sequence similarity of the bli-4 gene products with members of the kex $2 /$ subtilisin-like family of proprotein convertases implies a conserved functional activity in the nematode. Alternative splicing of bli-4 transcripts results in the putative production of enzymes with structurally different carboxyl termini, specifically a transmembrane domain-containing gene product and at least three proteins lacking a transmembrane domain.

\section{Expression pattern of a bli-4/lacZ fusion gene}

A bli-4/lacZ promoter fusion gene was constructed to analyze the expression pattern of bli-4. An $\sim 5$-kb XbalClaI genomic fragment (see Materials and methods) containing sequences at the $5^{\prime}$ end of the bli-4 gene was inserted into the lac $Z$ expression vector pPD21.28 (Fire et al. 1990). Transgenic animals carrying the construct were isolated and examined by staining with X-gal. Examination of adult and larval transgenic animals re- vealed lacZ expression in all hypodermal cells, the vulva, and the ventral nerve cords (Fig. 7A,B). Expression was first observed in embryos at the twofold stage (Fig. $7 \mathrm{Cl}$ just before the developmental time of arrest seen for the bli-4 lethal mutants. Staining appears to be localized to the nuclei of the hypodermal cells in the embryo.

\section{Deletion of sequences in e937 eliminates blisterase A expression}

Restriction fragment length polymorphism (RFLP) analysis revealed a $3.5-\mathrm{kb}$ deletion within the bli-4 gene in animals homozygous for the $e 937$ mutation. To characterize the mutation further, the deletion endpoints were sequenced and demonstrated to remove the last exon encoding the unique $3^{\prime}$ end of blisterase A (see Fig. 3A). The deletion was expected to result in the loss of expression of this isoform but not affect expression of the other bli-4 gene products. We examined expression of the bli-4 gene in $e 937$ homozygotes by Northern blot analysis. Poly $(\mathrm{A})^{+}$RNA isolated from both wild-type N2 animals and the mutant $e 937$ strain was probed using a restriction fragment common to all of the blisterase cDNAs. Four RNA species were observed in the wild-type lane (Fig. 8A), corresponding to RNAs of 2.3, 2.4, 2.7, and 3.2 $\mathrm{kb}$. The RNA species were identified tentatively by comparing the lengths of the transcripts with the characterized cDNAs (see Fig. 4). By this criteria we assigned identity of the $2.3-\mathrm{kb}$ transcript as that for blisterase $\mathrm{A}$, the 2.4-kb transcript corresponding to blisterase $B$, the 2.7$\mathrm{kb}$ transcript as blisterase $\mathrm{C}$, and the $3.2-\mathrm{kb}$ message encoding blisterase D. Hybridization of the "common" probe to $e 937$ poly $(\mathrm{A})^{+}$RNA identified only the $2.4-\mathrm{kb}$ and 3.2 -kb transcripts (Fig. $8 \mathrm{~A}$ ). This result indicated that the $2.3-\mathrm{kb}$ message, whose length is consistent with that predicted for the blisterase A cDNA, is missing in e937 animals. cDNAs isolated for blisterase $\mathrm{C}$ predict a 


\section{Thacker et al.}

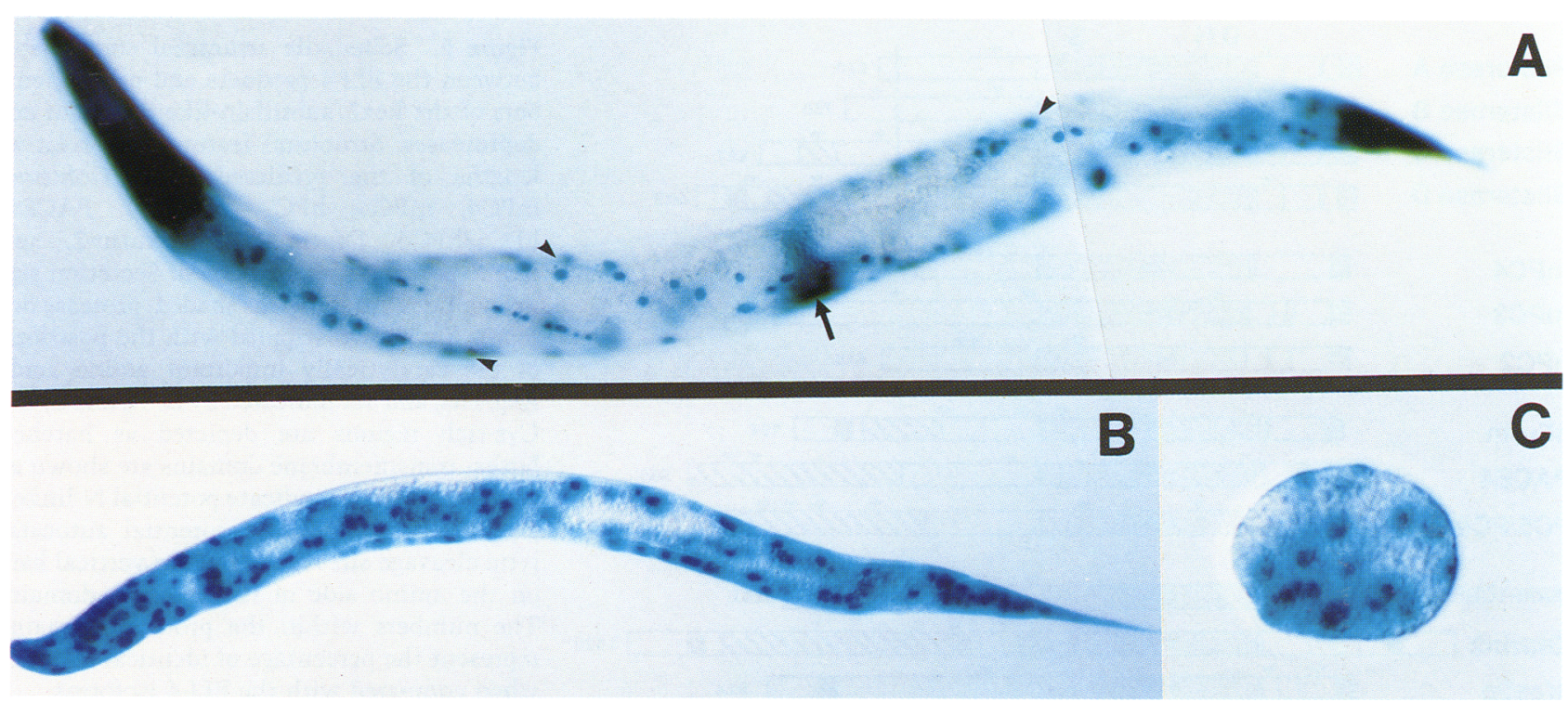

Figure 7. Expression pattern of a bli-4/lacZ promoter fusion gene. Expression of lac $Z$ was observed in all hypodermal cells, the vulva, and the ventral nerve cords. Shown here are examples of staining in an adult hermaphrodite $(A)$ and an $L 3$ larva $(B)$. lac $Z$ expression is first observed in late embryogenesis at about the twofold stage and is confined to hypodermal cells $(C)$. Arrowheads in $A$ represent expression within the hypodermal seam cells; the arrow indicates staining of the vulva.

message of $2.7 \mathrm{~kb}$ for this isoform. The $2.7-\mathrm{kb}$ message that hybridizes to the common probe is the correct size predicted for blisterase $C$, yet this transcript is missing in $e 937$ RNA. Because the exons specific to this isoform lie outside of the deletion breakpoints we would predict that expression of blisterase $\mathrm{C}$ would not be affected in $e 937$ animals. Therefore, we suspected that the $2.7-\mathrm{kb}$ message does not correspond to blisterase $C$. The identity of the $2.7-\mathrm{kb}$ transcript is unclear, although it may represent an alternative blisterase A message that uses a downstream polyadenylation site. However, we cannot rule out the possibility that the transcript encodes a fifth bli-4 gene product.

The 3.2-kb RNA has the size predicted for blisterase D, assuming that the $\mathrm{D}$-specific message has the same $5^{\prime}$ end as blisterase $\mathbf{B}$. This was confirmed by rehybridizing the membrane with a probe containing sequences specific for blisterases $\mathrm{C}$ and $\mathrm{D}$. As expected, the $3.2 \mathrm{~kb}$ message hybridized to the probe (Fig. $8 \mathrm{~B}$ ), confirming the identity of the transcript as corresponding to blisterase D. A 2.7-kb transcript predicted to encode blisterase C was not observed using the blisterase $C / D$-specific probe, even after prolonged exposure (data not shown). Unfortunately, the low abundance of the $2.4-\mathrm{kb}$ and 2.7 $\mathrm{kb}$ RNAs and the small size of the unique exons for blisterases A, B, and C for use as probes, made it difficult to establish unequivocally to which of the messages the various cDNAs correspond, at least by Northern blot analysis.

To establish further the expression patterns of blisterases $\mathrm{A}, \mathrm{B}$, and $\mathrm{C}$ in $e 937$ animals, we used the technique of RT-PCR. First-strand cDNA was synthesized from total RNA isolated from wild-type $\mathrm{N} 2$ and $e 937$ animals. cDNA was then amplified using a sense primer corresponding to nucleotides 2088-2105 (of the blisterase B sequence shown in Fig. 4) that lie within exon 12 (a coding exon incorporated in all of the bli-4 gene products/, in combination with an antisense primer specific for each BLI-4 isoform. Primers that amplify a 220-bp product from the $C$. elegans ubiquitin-like gene $(u b l)$ (Jones and Candido 1993) were also included as a positive control. The results obtained for RT-PCR are shown in Figure $8 \mathrm{C}$. Products of the expected lengths for blisterase A (145 bp, lane b), blisterase B (195 bp, lane d), and blisterase $C$ (514 and $556 \mathrm{bp}$, lane $\mathrm{f}$ ) were obtained using wild-type RNA. The 556-bp blisterase $\mathrm{C}$ amplification product is the result of incomplete processing of the message and contains intron 17 . The blisterase $C$ variant encoded by this transcript can potentially encode another BLI-4 product as depicted in Figure 4 . Both the expected blisterase B (lane e) and blisterase C (lane g) products were amplified using $e 937$ RNA. No blisterase A product was amplified from $e 937$ RNA (lane c), confirming that expression of this isoform is eliminated in $e 937$ animals.

The results from Northern blot analysis and RT-PCR confirmed that blisterase A expression is eliminated in $e 937$ homozygotes because of the deletion of the $3^{\prime}$ exon specific to this isoform. Expression of blisterases B, C, and $\mathrm{D}$ is not eliminated by the mutation.

\section{Characterization of molecular lesions in three class II lethal mutants}

Restriction analysis of $h 1010$ genomic DNA identified a putative Tc1 insertion within the wild-type 1.3-kb EcoRI 


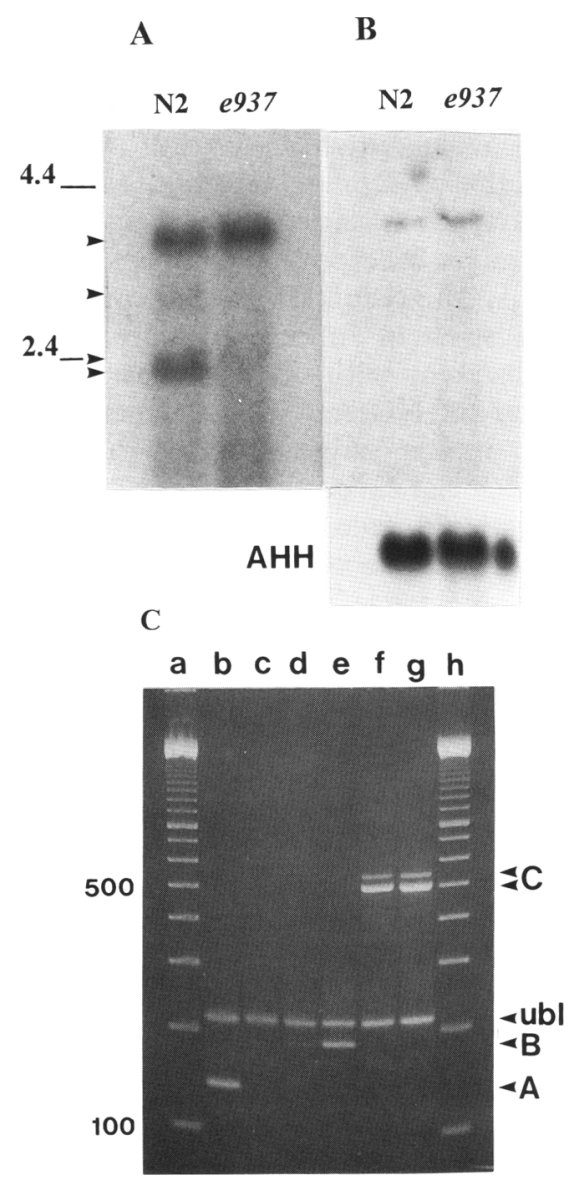

Figure 8. Northern and RT-PCR analysis of bli-4 expression in $\mathrm{N} 2$ and $e 937$ animals. Poly(A) ${ }^{+}$RNA from wild-type N2 and e937 animals was hybridized with a 480-bp ClaI-AccI fragment that is common to all of the blisterase cDNAs $(A)$. Transcripts that hybridized to the probe in the N2 lane (arrowheads) are 2.3, $2.4,2.7$, and $3.2 \mathrm{~kb}$. Both the 2.3- and the $2.7-\mathrm{kb}$ messages are missing in the $e 937$ lane. $(B)$ The same membrane hybridized with a probe specific for both blisterases $C$ and $D$, indicating that the $3.2-\mathrm{kb}$ message corresponds to the blisterase D cDNA. To standardize RNA levels, the membrane was rehybridized with a probe containing sequences for the $S$-adenosyl homocysteine hydrolase $(\mathrm{AHH})$ gene that recognizes a 1.6-kb transcript (inset under $B$ ). The numbers at left of $A$ represent the relative position of RNA molecular size markers (GIBCO-BRL RNA ladder). (C) RT-PCR analysis of blisterases $\mathrm{A}, \mathrm{B}$, and $\mathrm{C}$ expression in $\mathrm{N} 2$ and $e 937$ animals. Lanes $b, d$, and $f$ show amplification products obtained using N2 template RNA, and lanes $c, e$, and $g$, using $e 937$ template. Products obtained using primers specific for amplification of blisterase $\mathrm{A}$ are shown in lanes $b$ and $c$, amplification of blisterase $\mathrm{B}$ in lanes $d$ and $e$, and amplification of blisterase $C$ in lanes $f$ and $g$. The 220-bp product seen in all lanes is the result of amplification using primers designed from the $u b l$ gene, included as a positive control. Lanes $a$ and $h$ contain a 100-bp DNA ladder (GIBCO-BRL).

fragment. We verified this interpretation by determining the exact location of the transposon insertion by PCR amplification using bli-4- and Tc1-specific primers. Sequence generated from the amplified product showed that the Tc1 element had inserted into exon nine, resulting in the disruption of the bli-4 coding region/see Figs. $3 \mathrm{~A}$ and 4). Exon nine is common to all of the bli-4 gene products (see Fig. 3A). A second class II lethal allele, $q 508$, was isolated after mutagenesis with trimethylpsoralin and UV (kindly sent to us by Lisa Kadyk and Judith Kimble), mutagens known to cause a wide range of deletions in C. elegans (Yandell et al. 1994). We searched q508 genomic DNA for deletions within the first 12 exons common to all of the bli-4 gene products. This was accomplished using a series of primers, which when used for PCR amplification, generate overlapping products that cover the entire common region. Amplification of exons 11 and 12 using q508 template DNA yielded a product smaller than that generated from wildtype template (data not shown). Comparison of the amplified DNA sequences revealed a 366-bp deletion that results in the removal of the splice acceptor and $37 \mathrm{nu}-$ cleotides from exon 12 (see Figs. 3A and 4). In a third class II mutant, h199, an $\mathrm{A} \rightarrow \mathrm{T}$ transversion was identified that changes the codon for His 127 (CAT) into Leu (CTT). The $h 199$ lesion resides within exon four, which encodes a portion of the putative amino terminus, proximal to the protease domain (see Fig. 4).

All three mutations identified for the class II lethal mutants reside within coding exons common to all of the bli-4 gene products. On the basis of these findings, we propose that these lethal mutants affect the activity or expression of all isoforms.

\section{Discussion}

We have cloned the bli-4 locus by positioning the gene using the physical map of the $C$. elegans genome and have shown that it encodes members of the kex $2 /$ subtilisin-like family of proprotein cleavage enzymes. Our results demonstrate that bli-4 is contained within the cosmid K04F10, based on the detection of RFLPs associated with two mutations, and the ability to rescue fully the lethal phenotype of the class II lethal alleles, h1010, h199, and q508, the class III lethal allele $s 90$, and the blistered phenotype of $e 937$. The high degree of conservation within the catalytic domain suggests a structural and functional homology with other members of the proprotein convertase family.

\section{bli-4 encodes structurally diverse endoproteases}

bli-4 is an example of a proprotein convertase gene in which two types of enzyme arise from the same gene through alternative splicing. Structurally, the kex2/subtilisin-like convertase family can be divided into two classes based on the presence or absence of a transmembrane domain near the carboxyl terminus. Blisterase D falls into the class that contains a transmembrane domain, along with Kex2p, hFURIN, Dfurin-1 (all four isoforms|, and Dfurin-2. Blisterases $\mathrm{A}$ and $\mathrm{B}$ belong to the class of endoproteases that do not have a transmembrane domain, with an overall structural similarity to $\mathrm{PCl} /$ PC3, PC2, and PC4. Similarly, blisterase C resembles 
PC5/PC6 and PACE4 most closely. Although alternative splicing in other proprotein convertase genes has been reported, only Dfur-1 produces gene products that differ markedly in structure (Roebroek et al. 1992, 1994). At least two Dfur-1 isoforms show a nonoverlapping, restricted expression pattern (Roebroek et al. 1994). It is possible that the different proteins encoded by both the bli-4 locus and Dfur-1 perform distinct physiological roles in their respective organisms that, in mammalian cells, are fulfilled by many individual convertase genes.

\section{The e937 mutation eliminates the blisterase $A$ isoform}

We have demonstrated that the $e 937$ mutation is a 3.5$\mathrm{kb}$ deletion within the bli-4 gene that removes the 3 ' exon unique to blisterase A. Northern blot and RT-PCR analysis shows that the message encoding the blisterase A isoform is missing in $e 937$ animals, although a second less abundant transcript of $2.7 \mathrm{~kb}$ is also not observed (Fig. 8). The elimination of expression of the blisterase A isoform is consistent with what would be expected from the deletion breakpoints. Blisterase A appears to be required for the normal production or maintenance of the adult cuticle as evidenced by the viable blistered phenotype of $e 937$.

Northern blot analysis using the common probe showed that blisterases B and C are normally either expressed at very low levels or in a short developmental window. Whether the low abundance of these messages is a function of the short 3' UTRs found on both isoform cDNAs remains to be determined. Detection of an unprocessed blisterase $\mathrm{C}$ transcript by RT-PCR suggests inefficient splicing, although intron 17 has the capacity to encode a variant $C$ isoform. The sequence of the splice acceptor for intron 17 (TCTCCAG) is unusual when compared with most $C$. elegans genes (TTTTCAG) (Blumenthal and Thomas 1988). This may suggest a potential mechanism for controlling the expression of the blisterase $\mathrm{C}$ isoform, further resulting in the low abundance of this transcript.

The blistered phenotype is incompletely penetrant. The number of individuals that exhibit blisters in a given population is $\sim 90 \%$, and this fraction remains a heritable feature of $e 937$ homozygotes, regardless of their phenotype. Because C. elegans is hermaphroditic and strains are isogenic, incomplete penetrance would appear to correlate with the nature of the mutation in this complex gene. Although the molecular basis of penetrance is poorly understood, our preliminary analysis of the $e 937$ mutation may provide a first step toward determining the underlying mechanisms responsible for this phenomenon, at least with regard to bli-4. One possible explanation for the incomplete penetrance observed in $e 937$ homozygotes is that deletion of the blisterase A $3^{\prime}$ unique exon causes the bli-4 precursor RNA to be spliced instead to the $3^{\prime}$ exons of blisterases B, C, and D or combinations thereof. In this case, the alternative isoforms could compensate partially for the loss of blisterase A activity in $e 937$ homozygotes. We hypothesize that there exists a functional redundancy between the individual BLI-4 convertases. An observation consistent with such a hypothesis is that the blistered phenotype is fully penetrant in heteroallelic combinations of $e 937$ with most noncomplementing class II lethal alleles. If expression of the bli-4 gene products is eliminated completely by a class II mutation, there would be less blisterase $\mathrm{B}, \mathrm{C}$, and/or D activity to compensate for the loss of blisterase $\mathrm{A}$. The reduction in the compensating isoforms would result in animals that are more severely blistered, consistent with our observations. Rescue of both the lethal and blistered mutant phenotypes by constructs that encode only blisterase $\mathrm{A}$ and plasmid pCeh236 (which can encode blisterases B, C, and D) also suggests functional redundancy between the various BLI-4 isoforms. Rescue of the lethal mutants by constructs that only encode blisterase A is contradictory to what is observed for the $e 937$ mutation. The genetic data indicate that loss of blisterase A expression is not essential for development. One explanation for rescue by these plasmids is that expression from the extrachromosomal array may be aberrant.

The phenotype associated with the $e 937$ mutation suggests that blisterase A convertase activity is required for the production or maintenance of the adult cuticle. It could be that the cuticular collagens are substrates for cleavage by this isoform. Although no known mutations within $C$. elegans collagen genes result in a blistered phenotype, many of the cuticle collagens (e.g., rol-6 and sqt-1) contain an Arg-X-Lys/Arg-Arg motif within the amino termini (Kramer et al. 1990; Kramer and Johnson 1993|. Recently, it has been shown that mutations within these motifs disnupt normal collagen function implying that a kex $2 /$ subtilisin-like convertase activity may be required for processing of these cuticle collagens (Yang and Kramer 1994). Other candidate substrates for processing by the blisterases include five other genes in which mutations result in blistering of the cuticle (Brenner 1974; Park and Horvitz 1986). As yet, the molecular nature of these five blister mutants remains unknown.

\section{Class II lethal mutants contain mutations in the common coding region}

Molecular characterization of the lesions responsible for three class II lethal alleles has revealed that the mutations reside within the first 12 exons that are common to all of the BLI-4 isoforms. The h1010::Tc1 insertion site is within exon nine, suggesting that the presence of the transposon disrupts expression of all of the blisterases. The mutation $q 508$ is a deletion that affects exon 12 . We would predict that this lesion results in the complete lack of blisterase activity owing to the truncation of the bli-4 gene products. The deletion removes the splice acceptor and coding sequences from exon 12. Splicing of the upstream region to the unique $3^{\prime}$ exons, if it occurs, would effectively cause all of the remaining coding sequences to be out of frame. Thus, $q 508$ is a good candidate for a null mutation. The $h 1010$ and $q 508$ mutations both reside within a region of the blisterases that is uniquely conserved among all of the identified members 
of the kex2/subtilisin-like family and has been designated the "middle" domain (Van de Ven et al. 1990), or the "P-domain" in Kex2p (Fuller et al. 1991). Deletion analysis of Kex $2 p$ mutants has shown that the P-domain is essential for processing activity and may be required for either proper folding of the protease domain or recognition of substrates (Gluschankof and Fuller 1994). h199 contains an amino acid substitution that would also affect all bli-4 gene products. At present, we are unclear as to the exact mechanism by which this lesion reduces blisterase activity. A systematic search for mutations within the unique $3^{\prime}$ exons of the class III mutant, $s 90$, has failed so far to reveal any lesions. Because the $s 90$ mutant phenotype was rescued by K04F10 and subclones of the cosmid, the responsible mutation may be elsewhere within the bli-4 locus.

Preliminary analysis of animals homozygous for the lethal alleles of bli-4 suggests that development does not arrest until the end of embryogenesis. This could indicate that bli-4 is not required until later stages of embryonic development, which is consistent with the earliest time of expression observed for the bli-4/lacZ fusion gene. It is also possible that a maternal endowment of bli-4 activity provides mutants with sufficient blisterase function to survive to this stage. The similarity of the bli-4 lethal mutant phenotype with that shown by cuticle-defective mutants suggests that blisterase activity is required for elongation of the nematode embryo.

Of the other members of the kex 2 /subtilisin-like gene family, only $K E X 2$ was identified by genetic analysis; null mutations in $K E X 2$ result in the inability to process the $\alpha$-mating factor pheromone and the Kl killer toxin (Leibowitz and Wickner 1976; Wickner and Leibowitz 1976). KEX2 is not required for viability in yeast, indicating that Kex $2 p$ does not play an essential intracellular role. In contrast, potential null mutations in bli-4 result in developmental arrest near the end of embryogenesis before hatching. Such evidence demonstrates that bli-4 is essential to development, and implies the existence of blisterase substrates required for embryogenesis. Such substrates could include both structural molecules and peptide signals. Although essential function involving a secreted protein derived from a proprotein has not yet been described in C. elegans, the disruption of development by bli-4 mutants implies the existence of such interactions.

\section{Materials and methods}

\section{Nematode strains and culture conditions}

Worms were maintained on NGM growth media as described by Brenner (1974). Nomenclature used conforms to the uniform system for C. elegans (Horvitz et al. 1979). Nomenclature for translocations conforms to that used by McKim et al. (1988). The bli-4(e937) allele was isolated using ${ }^{32} \mathrm{P}$ (Babu 1974; Brenner 1974). Most of the class II lethal mutants were identified previously from a set of lethal mutations induced in ethylmethane sulfonate (EMS) screens (Howell et al. 1987; Peters et al. 1991; C. Thacker, M. Srayko, and A.M. Rose, unpubl.|. Additional alleles of this class not discussed in this study include $h 42$
(Howell et al. 1987), h254, h384, h427, h520, h699, h791 (Peters et al. 1991), $h 670$, and $h 1403$ (C. Thacker, M. Srayko, and A.M. Rose, unpubl.). h1010 was a spontaneous allele isolated in a precomplementation screen for bli-4 alleles in a mut- 6 background (Peters et al. 1991). h1010 was balanced by the translocation $s z T I\langle I ; X)$, which completely suppresses recombination on the left-half of LG I (Fodor and Deak 1985; McKim et al. $1988)$ in a strain of the genotype szTI $(I ; X)$ [lon-2]/unc-63(e384) bli-4(h1010) unc-13(e450) I. The lethal alleles of bli-4 were balanced by $s D p 2(I ; f)$, which is a free duplication of the left-third of LG $I$ (Rose et al. 1984). These bli-4 lethal alleles were maintained in strains having the genotype $s D p 2$; dpy-5(e61) bli-4(hx) unc-13(e450) $I$. The class III allele $s 90$ was isolated by Rose and Baillie (1980) and was maintained as $s D p 2$; bli-4(s90) unc13(e51) I. JK1723, genotype bli-4(q508)/dpy-5(e61) unc-87(e843) $I$, was isolated by L. Kadyk and J. Kimble (University of Wisconsin, Madison) after mutagenesis with trimethylpsoralen and UV. Other strains used in this study were KR2997, genotype sDp2; dpy-5(e61) bli-4(h199) unc-13(e450); KR2728, genotype sDp2; dpy-5(e61) bli-4(s90) unc-13(e450); KR2572, genotype sDp2; dpy-5(e61) bli-4(q508) I; KR2276, genotype unc-11(e47) I; $h E x 4$, and KR2872, genotype bli-4(e937) I; hEx6.

\section{Aligning the physical and genetic maps for the bli-4 region}

bli-4 was mapped with respect to $d p y-5$ and $u n c-13$ by RFLP analysis as described by Baillie et al. (1985). bli-4 was placed $\sim 0.3$ map units to the right of the polymorphism hP5. The cosmid corresponding to the $h P 5$ site is T09H3. The DNA density in this region was $\sim 500 \mathrm{~kb}$ per map unit (Starr et al. 1989), predicting that bli-4 would be located $\sim 150 \mathrm{~kb}$ to the right of hPS (see Fig. 2). The deficiency hDf8 maps to the right of bli-4. The left breakpoint of $h D f 8$ was mapped to the cosmid C44D1 1 by restriction analysis. Together, these results positioned the bli-4 coding region to cosmids located to the right of T09H3 and to the left of C44D1 1 on the physical map (Fig. 2). To determine the exact position of bli-4 sequences, cosmids that span this region together were used to probe for RFLP in genomic DNA prepared from various bli-4 mutants.

\section{Rescue of the blistered and lethal phenotypes}

We used a transgenic nematode strain, KR2276 (kindly provided by J. McDowall), that carries an extrachromosomal array designated $h E x 4$, composed of two overlapping cosmids K04F 10 and C29F10 and the plasmid pRF4. The cosmid C29F10 overlaps K04F 10 by $95 \%$ (data not shown) and was included to facilitate homologous recombination between the various clones to generate the array. The plasmid pRF4 contains the rol- 6 gene bearing the semidominant mutation su1006 that confers a righthanded Roller phenotype to animals that carry the array (Mello et al. 1991). As a control, all the genetic crosses outlined below were repeated using a transgenic strain (KR2872) that carries only the plasmid pRF4 as an extrachromosomal array (hEx6).

Rescue of e937 Homozygous e937 males were crossed with KR2276 Rol-6 hermaphrodites. All Rol-6 hermaphrodites obtained in the $F_{1}$ were isolated and allowed to self-fertilize. NonUnc-11 Rol-6 hermaphrodites were isolated until no Unc-11 animals were recovered indicating homozygosity for $e 937$. Several Rol-6 lines were established that segregated Rol-6 (wildtype) and Bli-4 progeny. No Bli-4 Rol-6 animals have ever been observed over many generations. However, Bli-4 Rol-6 animals were obtained using the control transgenic strain in parallel experiments. 
Rescue of h1010 Spontaneous Lon-2 males of the genotype szT1 $(I ; X)[$ lon-2] unc-63 bli-4(h1010) unc-13; I were crossed to KR2276 Rol-6 hermaphrodites. Successful rescue was determined by the presence of Unc-13 hermaphrodites in the $\mathrm{F}_{2}$ generation. unc-13 is epistatic to unc-63 and rol-6. To verify the presence of the rol-6 marker, rescued animals were mated with wild-type males. Rol- 6 animals were obtained in the $F_{1}$ progeny. No Unc- 13 progeny were obtained using the control Rol- 6 array. The presence of the h1010::Tc1 within the Unc-13 animals was verified by PCR using primers KRp36 and p618 (see below).

Rescue of q508 and s90 Heterozygous males of the genotype dpy-5 bli-4(q508)/ + + , or bli-4(s90) unc-13/ + + were crossed with KR2276 Rol-6 hermaphrodites. All Rol-6 hermaphrodites in the $F_{1}$ generation were isolated and allowed to self-fertilize. Successful rescue was determined by the presence of Dpy- 5 progeny in the case of $q 508$ or the presence of Unc-13 progeny in the $\mathrm{F}_{2}$ generation for $s 90$. No such progeny were obtained using the control transgenic strain. The presence of the $q 508$ deletion within the rescued Dpy- 5 animals was verified by PCR using the primers KRp46 and KRp47 (see below). A similar strategy was used for rescue experiments using the K04F10 subclones shown in Figure 3B. Heterozygous males of the genotype dpy-5 bli-4(q508)/ + +, dpy-5 bli-4(s90) unc-13/ + + + or dpy-5 bli-4(h199) unc-13/ + + + were crossed to Rol-6 hermaphrodites bearing pRF4 and the plasmid constructs. Successful rescue was determined by the presence of Dpy-5 progeny in the case of $q 508$ or the presence of Dpy-5 Unc-13 progeny in the $\mathrm{F}_{2}$ generation for $s 90$ and h199. Individual lines for each rescue were established and observed to give a fraction of dead progeny, resembling the bli-4 lethal phenotypes. Outcrossing of the putative rescued lines produced Rol progeny. Partial rescue of blistering by pCeh 238 was evidenced from four independent stable transgenic lines of genotype bli-4(e937); $h E_{x} 46$ to 49 (pCeh238 + pRF4). The percentage of Rol- 6 animals that blister in each of these lines is $43 \%(79 / 185), 8 \%(41 / 523), 17 \%(17 / 101)$, and $3 \%$ $(7 / 206)$, respectively, indicating incomplete rescue of the blistered phenotype.

\section{Isolation and characterization of bli-4 cDNA clones}

cDNA clones were isolated from a $\lambda$ ZAP library (Barstead and Waterston 1989) or provided by Yuji Kohara (National Institute of Genetics, Mishima, Japan; cDNA clone groups YK849 and YK949). The cDNA sequence was obtained from nested exonuclease III deletions as described by Henikoff (1984) and various fragments subcloned into pBluescript (Stratagene). Sequencing was performed using either Sequenase (U.S. Biochemical) or the Amplitaq DNA polymerase sequencing kit (ABI) and a PerkinElmer Cetus thermal cycler. Some sequence was obtained using an $\mathrm{ABI}$ model 373A automated sequencing machine. DNA and protein data base searches were performed using the FASTA program (Pearson and Lipman 1988). The PCgene (Intelligenetics) package of programs was used to identify the secretion signal peptide, hydrophobic domain, and potential glycosylation and cell attachment sites.

\section{K04F10 subclones}

Subclones used for transgenic rescue of bli-4 phenotypes presented in Figure 3B are as follows. pCeh226 contains a $13.5-\mathrm{kb}$ XbaI-Xhol insert containing exons 1-13. pCeh226 was digested with SalI and recircularized to obtain pCeh229. pCeh230 contains the same sequences as pCeh229 except for the deletion of a 1.8 -kb PstI-EcoRI fragment within intron 12. Subclones pCeh226, pCeh229, and pCeh230 encode blisterase A. pCeh238 contains a 10.3-kb XbaI-EcoRI fragment (including exons 1-12) fused to a $0.7-\mathrm{kb}$ Bam $\mathrm{HI}-\mathrm{KpnI}$ fragment that contains exons 14 and 15. This construct encodes blisterase B. pCeh236 contains exons 1-12, and 14-21 and can encode blisterases B, C, and D. The construction of pCeh239 is discussed below. These constructs were coinjected with pRF4 (1:1 ratio) into the germ line of $e 937$ homozygotes (or N2 animals for pCeh239). Stable transgenic lines were recovered and used for subsequent crosses to lethal-bearing strains discussed above. Rol-6 hermaphrodites containing pCeh239 (see below) were crossed to $e 937$ homozygous males. Bli-4 Rol-6 animals exhibiting approximately the same penetrance as $e 937$ homozygotes in the $\mathrm{F}_{2}$ generation indicated failure of pCeh239 to rescue blistering.

\section{Construction and expression of the bli-4/lacZ fusion}

A $5-\mathrm{kb} X b a \mathrm{I}-\mathrm{ClaI}$ fragment containing the putative promoter region of bli-4 was cloned into the $X b a I-B a m H I$ sites of the lac $Z$ expression vector pPD21.28 (Fire et al. 1990). The ClaI site in the bli.4 gene occurs 10 nucleotides after the putative initiator methionine codon in exon 2 . This plasmid was designated pCeh239 and used to transform N2 hermaphrodites as described above. Transgenic Rol-6 lines were fixed and stained with X-gal according to the procedure described by Fire et al. (1990).

\section{PCR amplification of the h1010::Tcl and q508 mutations}

Template DNA from individual arrested embryos homozygous for each of the mutant bli-4 alleles was extracted as described (Barstead et al. 1991). The PCR conditions used to amplify the $\mathrm{Tc} 1$ insertion in $h 1010$ were as follows: $94^{\circ} \mathrm{C} 45 \mathrm{sec} ; 50^{\circ} \mathrm{C} 30$ sec; $72^{\circ} \mathrm{C} 1 \mathrm{~min}$ for 30 cycles. The sequence of the primers used for the amplification were KRp36 (5'-CTATAAACCCTTAAT TTG TC-3') (bli-4 specific: anneals to a sequence within intron 7) and p618 (5'-GAACACTGTGGTGAAGTTTC-3') (Tc1 specific). p618 was a gift from $B$. Williams (Washington University School of Medicine, St. Louis, MO). The PCR conditions used to amplify the deletion from DNA extracted from homozygous q508-arrested embryos were the same as above except that the annealing temperature was $56^{\circ} \mathrm{C}$. The primers used to amplify the deletion were KRp46 (5'-ATGCTACTGGTCAGTTTTCA3') (anneals to a sequence within intron 10) and KRp47 (5'ATTCTATCCGAATCCTCCGA-3') (anneals to a sequence within intron 12). The PCR products obtained using these conditions were cloned into the pBluescript vector and sequenced using Sequenase version 2.0.

\section{Detection of the h199 mutation}

h199 was detected by a systematic search through exons 1-10 by heteroduplex mismatch detection using the mutation-detection enhancement (MDE) system (AT Biochemicals). Individual blistered $h 199 / e 937$ animals were used as template for independent PCR reactions to amplify overlapping sections of genomic DNA from the region encoding exons 1-10. After running denatured/reannealed PCR products in the nondenaturing gel matrix $(40 \times 20 \mathrm{~cm} \times 1 \mathrm{~mm})$ for $21 \mathrm{hr}$ at $20 \mathrm{~V} / \mathrm{cm}$, a polymorphism was detected in a 433-bp fragment amplified from three independent PCR reactions by KRp44 15'-TGTTGAACGATTGGATTCAC-3') (sense primer corresponding to nucleotides 456-474) and KRp45 (5'-ATACATATCCACCAACTGCT-3') (antisense primer corresponding to nucleotides 702-721). Homozygous-arrested embryos from a heterozygous h199/e937 parent were used as template for PCR using KRp44 and KRp45. Three independent reaction products were cloned and sequenced to reveal an $\mathrm{A} \rightarrow \mathrm{T}$ transversion (nucleotide position 
560 in Fig. 4) when compared to sequence obtained from parallel experiments with $\mathrm{N} 2$ and $e 937$ worms as template for PCR.

\section{Northern blot analysis}

Mixed stage total N2 $C$. elegans RNA and mixed stage total bli-4(e937) RNA was isolated by centrifugation of nematode lysates prepared in guanidinium thiocyanate through $\mathrm{CsCl}$ gradients (Chirgwin et al. 1979; Kramer et al. 1985). Poly(A) ${ }^{+}$RNA was purified using the PolyATtract mRNA isolation system (Promega), according to the manufacturer's conditions. Five micrograms of poly $(\mathrm{A})^{+}$RNA was denatured in $2.2 \mathrm{M}$ formaldehyde, $50 \%$ deionized formamide, and $1 \times$ MOPS for $15 \mathrm{~min}$ at $60^{\circ} \mathrm{C}$. The RNA was fractionated by electrophoresis in an $0.8 \%$ agarose gel containing $1 \times$ MOPS and $2.2 \mathrm{~m}$ formaldehyde $(\mathrm{pH}$ 7.0). RNA was transferred to a Zeta-probe membrane (Bio-Rad) and hybridized with random-primed (Feinberg and Vogelstein $1983)^{32}$ P-labeled probes in $0.25 \mathrm{M} \mathrm{Na}_{2} \mathrm{HPO}_{4}$ (pH 7.2), $7 \%$ SDS at $65^{\circ} \mathrm{C}$. The membrane was washed in $0.3 \times$ SSC, $0.1 \%$ SDS, at $65^{\circ} \mathrm{C}$. The common probe used was a ClaI-AccI 480 -bp fragment corresponding to nucleotides 1609-2089 of the blisterase B cDNA (Fig. 4), which lies just 3' of the protease domain and is common to all of the blisterases. The blisterase C/D-specific probe was a SacI-BamHI 518-bp fragment corresponding to nucleotides 2239-2757 within the blisterase D sequence shown in Figure 4 . The first 275 bp of this fragment are shared by blisterase $C$; hence, the probe should hybridize to both the $C$ and $D$ transcripts. To standardize RNA levels, the membrane was stripped and rehybridized with a $1.7-\mathrm{kb}$ probe containing genomic sequences encoding the $C$. elegans $S$-adenosyl homocysteine hydrolase $(\mathrm{AHH})$ gene.

\section{$R T-P C R$}

First-strand cDNA was synthesized from $5 \mu \mathrm{g}$ of total RNA using a $\mathrm{dT}_{12-18}$ primer and the Superscript Preamplification system (GIBCO-BRL). The conditions used were as described by the manufacturer. The primers used for amplification of first-strand cDNA were as follows (see also Fig. 4): KRp6 (5'-CTACTCGGCTACTCCTGC-3') (nucleotides 2088-2105 in exon 12, common to all of the bli-4 gene products); KRp49 (5'-TCTATGAAGCTGTGAGCAGT-3') (antisense primer corresponding to nucleotides 2209-2228 of the blisterase A-specific 3' exon); KRp50 (5'-ATGGGTACGAGAAGAAGAGT-3') (antisense primer corresponding to nucleotides 2261-2280 of the blisterase B-specific $3^{\prime}$ exon), and KRp39 (5'-TAAAGGCGCTCGGCTTTTTG-3') (antisense primer corresponding to nucleotides 2583-2602 of the blisterase C-specific exon 18). Primers OPC18.r and OPC19.c, which are specific for the $u b l$ gene (Jones and Candido 1993), were used as an internal positive control. Amplification reactions were performed in which the primer KRp6 was used in combination with one of the antisense primers specific for each BLI-4 isoform, along with the control $u b l$ gene primers. Reaction mixtures for PCR contained a 1- $\mu$ l aliquot of the cDNA template, 50 pmoles of each primer, and 2.5 units of Taq DNA polymerase (Promega) in $50 \mathrm{mM} \mathrm{KCl}, 10 \mathrm{mM}$ Tris- $\mathrm{HCl}$ (pH 8.3), $0.1 \%$ Triton X-100, $1.5 \mathrm{mM} \mathrm{MgCl}_{2}$, and 200 $\mathrm{mM}$ dNTPs in a final volume of $25 \mu \mathrm{l}$. Reactions were carried out in a Perkin-Elmer Cetus thermal cycler for 32 cycles of denaturation $\left(94^{\circ} \mathrm{C}, 45 \mathrm{sec}\right)$, annealing $\left(59^{\circ} \mathrm{C}, 30 \mathrm{sec}\right)$, and extension $\left(72^{\circ} \mathrm{C}, 1 \mathrm{~min}\right)$ followed by extension at $72^{\circ} \mathrm{C}$ for $7 \mathrm{~min}$.

Determination of the $5^{\prime}$ end of bli-4 was as follows. RT-PCR was performed on poly $(A)^{+}$RNA from N2 worms. First-strand cDNA was synthesized as above. The resultant cDNA was amplified with KRpl0 (5'-ACTCTCTTCTTCGGTCGC-3') (antisense primer corresponding to nucleotides $504-521$ of exon
3) and a sense primer derived from SLl (including a NotI adapter) (5'-ATAAGAATGCGGCCGCGGTTTAATTACCCAGTTG- $\left.3^{\prime}\right)$. A product of the expected size for KRp10 with SL1 ( $\sim 500 \mathrm{bp})$ was reamplified using SLl and the nested primer KRp11 (5'-GTGTCCTTGTTGTTTCCG-3') (antisense primer corresponding to nucleotides $418-436$ of exon 3 ). The resulting product was cloned and sequenced to confirm that bli-4 is transspliced to SL1. A parallel experiment performed with an SL2 trans-splice leader primer failed to amplify bli-4 sequences. Reaction conditions for PCR were as described above except the annealing temperature for initial amplification on first strand cDNA was $56^{\circ} \mathrm{C}$ and reamplification was at $58^{\circ} \mathrm{C}$.

\section{Note}

The accession numbers for the cDNA sequences reported in this paper are L29438, L29439, and L29440.

\section{Acknowledgments}

We wish to thank Gary Thomas, Carolyn Brown, David Baillie, Mark Edgley, Marco Marra, and Anna Tinker for helpful discussions concerning the manuscript, Betty Leung for technical assistance with the automated sequencer, Lisa Kadyk and Judith Kimble for the $q 508$ mutant, Jennifer McDowall for the transgenic strain KR2276, Yuji Kohara for additional cDNA clones and sequence, Ben Williams for the p618 Tc1 primer, and Don Jones and Peter Candido for the $u b l$ specific primers. Some nematode strains used in this study were provided by the Caenorhabditis Genetics Center, which is funded by the NIH National Center for Research Resources. This research was supported by grants from the Medical Research Council of Canada and the British Columbia Health Research Foundation to A.M.R. and a Medical Research Council of Canada Studentship to K.P., and by equipment purchased with grants from the British Columbia Health Research Foundation.

The publication costs of this article were defrayed in part by payment of page charges. This article must therefore be hereby marked "advertisement" in accordance with 18 USC section 1734 solely to indicate this fact.

\section{References}

Babu, P. 1974. Biochemical genetics of C. elegans. Mol. \& Gen. Genet. 135: 39-44.

Baillie, D.L., K.A. Beckenbach, and A.M. Rose. 1985. Cloning within the unc-43 to unc-31 interval (linkage group IV) of the Caenorhabditis elegans genome by $\mathrm{Tc} 1$ linkage selection. Can. I. Genet. Cytol. 27: 457-466.

Barr, P.J. 1991. Mammalian subtilisins: The long-sought dibasic processing endoproteases. Cell 66: 1-3.

Barstead, R.J. and R.H. Waterston. 1989. The basal component of the nematode dense-body is vinculin. /. Biol. Chem. 264: 10177-10185.

Barstead, R.J., L. Kleiman, and R.H. Waterston. 1991. Cloning, sequencing, and mapping of an $\alpha$-actinin gene from the nematode Caenorhabditis elegans. Cell Motil. Cytoskel. 20: 6978.

Blumenthal, T. and J. Thomas. 1988. Cis and trans mRNA splicing in C. elegans. Trends Genet. 4: 305-308.

Brenner, S. 1974. The genetics of Caenorhabditis elegans. Genetics 77: 71-94.

Bresnahan, P.A., R. Leduc, L. Thomas, J. Thorner, H.L. Gibson, A.J. Brake, P.J. Barr, and G. Thomas. 1990. Human fur gene encodes a yeast KEX2-like endoprotease that cleaves pro- 
beta-NGF in vivo. $J$. Cell Biol. 111: 2851-2859.

Chan, S.J., A.A. Oliva Jr., J. LaMendola, A. Grens, H. Bode, and D.F. Steiner. 1992. Conservation of the prohormone convertase gene family in metazoa: Analysis of cDNAs encoding a PC3-like protein from hydra. Proc. Natl. Acad. Sci. 89: 6678-6682.

Chirgwin, J.M., A.E. Przybyla, R.J. MacDonald, and W.J. Rutter. 1979. Isolation of biologically active ribonucleic acid from sources enriched in ribonuclease. Biochemistry 18: 5294 5299.

Coulson, A., J. Sulston, S. Brenner, and J. Karn. 1986. Towards a physical map of the genome of the nematode Caenorhabditis elegans. Proc. Natl. Acad. Sci. 83: 7821-7825.

Coulson, A., R. Waterston, J. Kiff, J. Sulston, and Y. Kohara. 1988. Genome linking with yeast artificial chromosomes. Nature 355: 184-186.

Docherty, K. and D.F Steiner. 1982. Post-translational proteolysis in polypeptide hormone biosynthesis. Annu. Rev. Physol. 44: 625-638.

Feinberg, A.P. and B. Vogelstein. 1983. A technique for radiolabeling DNA restriction endonuclease fragments to high specific activity. Anal. Biochem. 137: 266-267.

Fire, A., S.W. Harrison, and D. Dixon. 1990. A modular set of $l a c Z$ fusion vectors for studying gene expression in Cae norhabditis elegans. Gene 113: 189-198.

Fodor, A. and P. Deak. 1985. The isolation and genetic analysis of a Caenorhabditis elegans translocation (szT1) strain bearing an X-chromosome balancer. J. Genet. 64: 143-157.

Fuller, R.S., R.E Sterner, and J. Thorner. 1988. Enzymes required for yeast prohormone processing. Annu. Rev. Physiol. 50: 345-362.

Fuller, R.S., A. Brake, and J. Thorner. 1989a. Yeast prohormone processing enzyme (KEX2 gene product) is a $\mathrm{Ca}^{2+}$-dependent serine protease. Proc. Nat1. Acad. Sci. 86: 1434-1438.

Fuller, R.S., A.J. Brake, and J. Thorner. 1989b. Intracellular targeting and structural conservation of a prohormone-processing endoprotease. Science 246: 482-486.

Fuller, R.S. C. Brenner, P. Gluschankof, and R.S. Wilcox. 1991. The yeast prohormone-processing KEX2 protease, an enzyme with specificity for paired basic residues. In Advances in life sciences: Methods in protein sequence analysis led. Jornvall, H., J.-O. Hoog, and A.-M. Gustavsson/, pp. 205-214. Birhauser, Berlin, Germany.

Gluschankof, P and R.S. Fuller. 1994. A C-terminal domain conserved in precursor processing proteases is required for in tramolecular $\mathrm{N}$-terminal maturation of pro-Kex 2 protease. EMBO J. 13: 2280-2288.

Gómez-Saladín, E., D.L. Wilson, and I.M. Dickerson. 1994. Isolation and in situ localization of a cDNA encoding a Kex2like prohormone convertase in the nematode Caenorhabditis elegans. Cell. Mol. Neurobiol. 14: 9-25.

Hayflick, J.S., W.J. Wolfgang, M.A. Forte, and G. Thomas. 1992. A unique Kex-2 like endoprotease from Drosophila melanogastor is expressed in the central nervous system during early embryogenesis. $J$. Neurosci. 12: 705-717.

Henikoff, S. 1984. Unidirectional digestion with exonuclease III in DNA sequence analysis. Gene 28: 351-259.

Horvitz, H.R., S. Brenner, J. Hodgkin, and R. Herman. 1979. A uniform genetic nomenclature for the nematode Caenorhabditis elegans. Mol. \& Gen. Genet. 175: 129-133.

Hosaka, M., M. Nagahama, W.-S. Kim, T. Watanabe, K. Hatsuzawa, J. Ikemizu, K. Murakami, and K. Nakayama. 1991. Arg-X-Lys/Arg-Arg motif as a signal for precursor cleavage catalysed by furin within the constitutive secretory pathway. J. Biol. Chem. 266: 12127-12130.

Howell, A.M., S.G. Gilmore, R.A. Mancebo, and A.M. Rose.
1987. Genetic analysis of a large autosomal region in Caenorhabditis elegans by the use of a free duplication. Genet. Res. 49: 207-213.

Ikemura, H. and M. Inouye. 1988. In vitro processing of prosubtilisin produced in Escherichia coli. J. Biol. Chem. 263: 12959-12963.

Jones, D. and E.P.M. Candido. 1993. Novel ubiquitin-like ribosomal protein fusion genes from the nematodes Caenorhabditis elegans and Caenorhabditis briggsae. 1. Biol. Chem. 268: 19545-19551.

Kiefer, M.C., J.E. Tucker, R. Joh, K.E. Landsberg, D. Saltman, and P.J. Barr. 1991. Identification of a second human subtilisin-like protease gene in the fes/fps region of chromosome 15. DNA Cell Biol. 10: 757-769.

Kramer, J.M. and J.J. Johnson. 1993. Analysis of mutations in the sqt-1 and rol-6 collagen genes of Caenorhabditis elegans. Genetics 135: 1035-1045.

Kramer, J.M., G.N. Cox, and D. Hirsh. 1985. Expression of the Caenorhabditis elegans collagen genes col-1 and col-2 is developmentally regulated. J. Biol. Chem. 260: 1945-1951.

Kramer, J.M., R.P. French, E-C. Park, and J.J. Johnson. 1990. The Caenorhabditis elegans rol-6 gene, which interacts with the sqt-1 collagen gene to determine organismal morphology, encodes a collagen. Mol. Cell Biol. 10: 2081-2089.

Krause, M. and D. Hirsh. 1987. A trans-spliced leader sequence on actin mRNA in Caenorhabditis elegans. Cell 49: 735761.

Kyte, J. and R.F. Doolittle. 1982. A simple method for displaying the hydropathic character of a protein. J. Mol. Biol. 157: 105132.

Leduc, R., S.S. Molloy, B.A. Thorne, and G. Thomas. 1992. Activation of human furin precursor processing endoprotease occurs by an intramolecular autoproteolytic cleavage. J. Biol. Chem. 267: 14304-14308.

Liebowitz, M.J. and R.W. Wickner. 1976. A chromosomal gene required for killer plasmid expression, mating and sporulation in Saccharomyces cerevisiae. Proc. Natl. Acad. Sci. 73: 2061-2065.

Lusson, J., D. Vieau, J. Hamelin, R. Day, M. Chrétien, and N.G. Seidah. 1993. cDNA structure of the mouse and rat subtilisin/kexin-like PC5: A candidate proprotein convertase expressed in endocrine and nonendocrine cells. Proc. Natl. Acad. Sci. 90: 6691-6695.

McKim, K.S., A.M. Howell, and A.M. Rose. 1988. The effects of translocations on recombination frequency in Caenorhabditis elegans. Genetics 120: 987-1001.

Mello, C.C., J.M. Kramer, D. Stinchcomb, and V. Ambros. 1991. Efficient gene transfer in C. elegans: Extrachromosomal maintenance and integration of transforming sequences. EMBO I. 10: 3959-3970.

Mizuno, K., T. Nakamura, T. Ohshima, S. Tanaka, and H. Matsuo. 1988. Yeast KEX2 gene encodes an endopeptidase homologous to subtilisin-like serine proteases. Biochem. Biophys. Res. Commun. 156: 246-254.

Molloy, S.S., P.A. Bresnahan, S.H. Leppla, K.R. Klimpel, and G. Thomas. 1992. Human furin is a calcium-dependent serine endoprotease that recognizes the sequence Arg-X-X-Arg and efficiently cleaves anthrax toxin protective antigen. 1 . Biol. Chem. 267: 16396-16402.

Molloy, S.S., L. Thomas, J.K. VanSlyke, P.E. Stenberg, and G. Thomas. 1994. Intracellular trafficking and activation of the furin proprotein convertase: Localization to the TGN and recycling from the cell surface. EMBO $/$. 13: 18-33.

Mori, I., D.G. Moerman, and R.H. Waterston. 1988. Analysis of a mutator activity necessary for germline transposition and excision of Tc1 transposable elements in Caenorhabditis el- 
egans. Genetics 120: 397-407.

Nakayama, K., W.-S. Kim, S. Torii, M. Hosaka, T. Nakagawa, J. Ikemizu, T. Baba, and K. Murakami. 1992. Identification of the fourth member of the mammalian endoprotease family homologous to the yeast Kex 2 protease. J. Biol. Chem. 267: $5897-5900$.

Nakagawa, T., M. Hosaka, S. Torii, T. Watanabe, K. Murakami, and K. Nakayama. 1993. Identification and functional expression of a new member of the mammalian Kex2-like processing endoprotease family: Its striking structural similarity to PACE4. I. Biochem. 113: 132-135.

Park, E-C. and H.R. Horvitz. 1986. Mutations with dominant effects on the behavior and morphology of the nematode $C$. elegans. Genetics 113: 821-852.

Peters, K., J. McDowall, and A.M. Rose. 1991. Mutations in the bli-4 (I) locus of Caenorhabditis elegans disrupt both adult cuticle and early larval development. Genetics 129: 95-102.

Pearson, W.R. and D.J. Lipman. 1988. Improved tools for biological sequence comparison. Proc. Natl. Acad. Sci. 85: 2444-2448.

Power, S.D., R.M. Adams, and J.A. Wells. 1986. Secretion and autoproteolytic maturation of subtilisin. Proc. Natl. Acad. Sci. 83: 3096-3100.

Priess, J.R. and D.I. Hirsh. 1986. Caenorhabditis elegans morphogenesis: The role of the cytoskeleton in elongation of the embryo. Dev. Biol. 117: 156-173.

Roebroek, A.J.M., J.A. Schalken, J.A.M. Leunissen, C. Onnekink, H.P.J. Bloemers, and W.J.M.Van de Ven. 1986. Evolutionary conserved close linkage of the $c$-fes/fps proto-oncogene and genetic sequences encoding a receptor-like protein. EMBO J. 5: 2197-2202.

Roebroek, A.J.M., J.W.M. Creemers, I.G.L. Pauli, U. KurzikDumke, M. Rentrop, E.A.F. Gateff, J.A.M. Leunissen, and W.J.M. Van de Ven. 1992. Cloning and functional expression of Dfurin2, a subtilisin-like proprotein processing enzyme of Drosophila melanogastor with multiple repeats of a cysteine motif. J. Biol. Chem. 267: 17208-17215.

Roebroek, A.J.M., J.W.M. Creemers, I.G.L. Pauli, T. Bogaert, and W.J.M. Van de Ven. 1994. Generation of structural and functional diversity in furin-like proteins in Drosophila melanogaster by alternative splicing of the Dfur1 gene. EMBO I. 12: $1853-1870$.

Rose, A.M. and D.L. Baillie. 1980. Genetic organization of the region around unc-15 $(I)$, a gene affecting paramyosin in Caenorhabditis elegans. Genetics 96: 639-648.

Rose, A.M., D.L. Baillie, and J. Curran. 1984. Meiotic pairing behavior of two free duplications of linkage group I of Caenorhabditis elegans. Mol. \& Gen. Genet. 195: 52-56.

Ruoslahti, E. and M.D. Pierschbacher. 1986. Arg-Gly-Asp: A versatile cell recognition signal. Cell 44: 517-518.

Sambrook, J., E.F. Fritsch, and T. Maniatis. 1989. Molecular cloning: A laboratory manual. Cold Spring Harbor Laboratory Press, Cold Spring Harbor, New York.

Seidah, N.G., L. Gaspar, P. Mion, M. Marcinkiewicz, M. Mbikay, and M. Chrétien. 1990. cDNA sequence of two distinct pituitary proteins homologous to $\mathrm{Kex} 2$ and furin gene products: Tissue-specific mRNAs encoding candidates for pro-hormone processing proteinases. DNA Cell Biol. 9: 415424.

Seidah, N.G., M. Marcinkiewicz, S. Benjannet, L. Gaspar, G. Beaubien, M.G. Mattei, C. Lazure, M. Mbikay, and M. Chrétien. 1991. Cloning and primary sequence of a mouse candidate prohormone convertase $\mathrm{PCl}$ homologous to $\mathrm{PC} 2$, furin and Kex2: Distinct chromosomal localization and messenger RNA distribution in the brain and pituitary compared to PC2. Mol. Endocrinol. 5: 111-122.
Seidah, N.G. and M. Chrétien. 1992. Proprotein and prohormone convertases of the subtilisin family. Trends Endocrinol. Metab. 3: 133-140.

Seidah, N.G., R. Day, J. Hamelin, A. Gaspar, M.W. Collard, and M. Chrétien. 1992. Testicular expression of PC4 in the rat: Molecular diversity of a novel germ cell-specific kex2/subtilisin-like proprotein convertase. Mol. Endocrinol. 6: 15591570.

Smeekens, S.P. and D.F. Steiner. 1990. Identification of a human insulinoma cDNA encoding a novel mammalian protein structurally related to the yeast dibasic processing protease Kex2. J. Biol. Chem. 265: 2997-3000.

Smeekens, S.P., A.S. Avruch, J. LaMendola, S.J. Chan, and D.F Steiner. 1991. Identification of a cDNA encoding a second putative prohormone convertase related to PC2 in AtT20 cells and islets of Langerhans. Proc. Natl. Acad. Sci. 88: 340344.

Starr, T., A.M. Howell, J. McDowall, K. Peters, and A.M. Rose. 1989. Identification of DNA probes within the linkage group I gene cluster of Caenorhabditis elegans. Genome 32: 365372.

Thomas, G., B.A. Thorne, and D.E. Hurby. 1988. Gene transfer techniques to study neuropeptide processing. Annu. Rev. Physiol. 50: 323-332.

van den Ouweland, A.M., H.L. van Duijnhoven, G.D. Keizer, L.C. Dorssers, and W.J.M. Van de Ven. 1990. Structural homology between the human fur gene product and the subtilisin-like protease encoded by yeast KEX2. Nucleic Acids Res. 18: 664 .

Van de Ven, W.J.M., J. Voorberg, R. Fontijin, H. Pannekoek, A.M.W. van den Oweland, H.L.P. van Duijnhoven, A.J.M. Roebroek, and R.J. Siezen. 1990. Furin is a subtilisin-like proprotein processing enzyme in higher eukaryotes. Mol. Biol. Rep. 14: 265-275.

Waterston, R., C. Martin, M. Craxton, C. Huynh, A. Coulson, L. Hillier, R. Durbin, P. Green, R. Shownkeen, N. Halloran, M. Metzstein, T. Hawkins, R. Wilson, M. Berks, Z. Du, K. Thomas, J. Thierry-Mieg, and J. Sulston. 1992. A survey of expressed genes in Caenorhabditis elegans. Nature Genet. 1: 114-123.

Wickner, R.W. and M.J. Liebowitz. 1976. Two chromosomal genes required for killing expression in killer strains of Saccharomyces cerevisiae. Genetics 82: 429-442.

Wise, R.J., P.J. Barr, P.A. Wong, M.C. Kiefer, A.J. Brake, and R.J. Kaufman. 1990. Expression of a human proprotein processing enzyme: Correct cleavage of the von Willebrand factor precursor at a paired basic amino acid site. Proc. Natl. Acad. Sci. 87: 9378-9382.

Yandell, M.D., L.G. Edgar, and W.B. Wood. 1994. Trimethylpsoralen induces small deletion mutations in Caenorhabditis elegans. Proc. Natl. Acad. Sci. 91: 1381-1385.

Yang, I and J.M. Kramer. 1994. In vitro mutagenesis of Caenorhabditis elegans cuticle collagens identifies a potential subtilisin-like protease cleavage site and demonstrates that carboxyl domain disulphide bonding is required for normal function but not assembly. Mol. Cell Biol. 14: 2722-2730. 


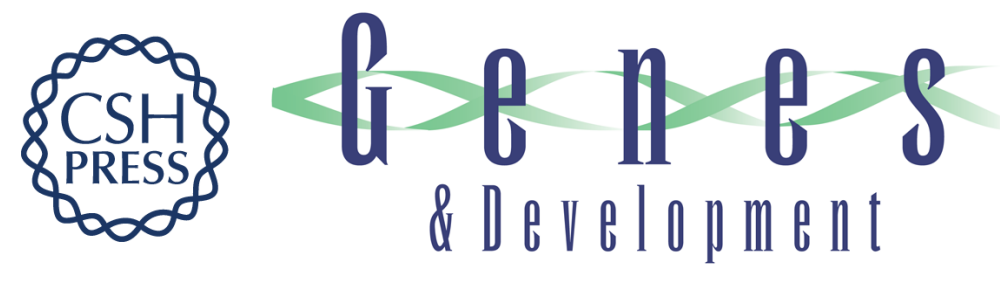

\section{The bli-4 locus of Caenorhabditis elegans encodes structurally distinct kex2/subtilisin-like endoproteases essential for early development and adult morphology.}

C Thacker, K Peters, M Srayko, et al.

Genes Dev. 1995, 9:

Access the most recent version at doi:10.1101/gad.9.8.956

References This article cites 70 articles, 31 of which can be accessed free at: http://genesdev.cshlp.org/content/9/8/956.full.html\#ref-list-1

License

Email Alerting Service

Receive free email alerts when new articles cite this article - sign up in the box at the top right corner of the article or click here.

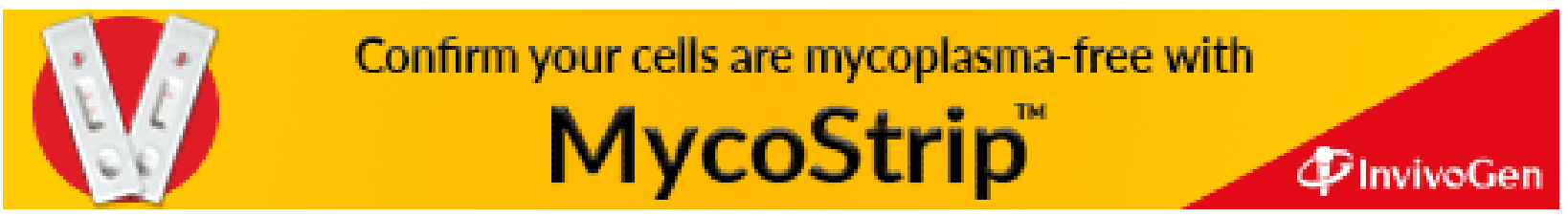

